\title{
Pratiques RH, culture et performance des organisations Revue de littérature théorique et empirique
}

\author{
RAJÂA Omar \\ Enseignant Chercheur à l'Ecole Nationale de Commerce et de Gestion \\ Université Ibn Zohr-Maroc
}

\begin{abstract}
Résumé : Cette revue de littérature théorique et empirique nous a permis de mieux appréhender les différentes approches qui ont abordé le rôle des pratiques RH dans la performance des organisations et d'exposer les principaux résultats des études effectuées partout dans le monde aussi bien dans la perspective unidimensionnelle que pluridimensionnelle. En premier lieu, nous avons présenté, l'approche économique, l'approche financière, l'approche stratégique et l'approche psychologique et de plus spécifiquement l'approche universaliste, l'approche de contingence et l'approche configurationnelle. En second lieu, après avoir exposé une synthèse quantitative de 235 résultats des 241 études empiriques et recherches effectuées entre 1978 et 2003 répertoriées en 2004 par Allouche et al., nous avons présenté quelques 123 confirmations empiriques du lien pratiques $\mathrm{RH}$, dont 7 traitant le cas marocain, et la performance des organisations effectuées partout dans le monde depuis 2004 et quelques 31 études illustrant la variable culturelle comme élément contingent et médiateur dans la relation pratiques RH et performance des organisations.
\end{abstract}

Mots-clés : Pratiques RH, Performance des organisations, Culture, Approches théoriques, Etudes empiriques.

Dès les années soixante-dix du vingtième siècle, la qualité des Ressources Humaines (RH) étaient présentée comme étant la variable déterminante de la performance exceptionnelle des entreprises japonaises. En effet, dès cette décennie les entreprises japonaises devenaient très compétitives par rapport aux entreprises américaines et européennes et ceci malgré que l'observation minutieuse de ces entreprises avait montré qu'elles ne disposaient ni de ressources naturelles et de facteurs de production meilleure marché, ni d'une organisation particulièrement différente ni de stratégies ingénieuses par rapport à leurs concurrentes. Ainsi, Athos et Pascal avaient considéré que les sociétés nipponnes possédaient un plus qui manquait cruellement aux entreprises occidentales: Les firmes japonaises dotaient leurs employés d'une sorte de supplément d'âme. Ces deux auteurs, en analysant un ensemble d'usages ancrés dans les mœurs et surtout faisaient partie de la culture organisationnelle nipponne, avaient affirmé que les valeurs qu'ils avaient qualifié de «trame spirituelle » ou d' "arme secrète » étaient créatrices d'objectifs supérieurs permettant de concilier la finalité de l'entreprise et les aspirations humaines ${ }^{1}$.

De ce fait, toute entreprise est appelée à revoir aussi bien leur mode de gestion que leur structure organisationnelle ${ }^{2}$ et les responsables RH sont appelés, aujourd'hui plus que n'importe quel moment, à développer au sein de leur établissement un ensemble d'usages qui peu à peu vont s'ancrer dans les mœurs pour faire partie de la culture qui deviendra une véritable variable structurelle capable de réguler les

\footnotetext{
${ }^{1}$ Athos A-G. et Pascale R-T. : « Le management est-il un art japonais ?», Paris, Les Éditions d'organisation, 1984.

${ }^{2}$ Lacoursière R., Fabi B., St-Pierre J. et Arcand M. : "Impact de certaines pratiques de GRH sur la performance organisationnelle et financières $\operatorname{des} \boldsymbol{P M E} », 12^{\text {ieme }}$ congrès de l'Association Internationale de Psychologie du Travail et des Organisations (AIPTO), Louvain la Neuve, Belgique, 2002, pp. 1-7.
} 
comportements des salariés en vue de contribuer au succès de leur organisation.

En parallèle, sur le plan académique, le facteur humain et particulièrement la relation susceptible d'exister entre les pratiques RH et la performance des organisations sont devenus depuis la deuxième moitié du $20^{\text {ième }}$ siècle un sujet d'études auquel s'intéressait un grand nombre de chercheurs et cette mouvance s'est poursuivie au début du $21^{\text {ième }}$ siècle avec une large diffusion dans plusieurs pays du globe.

Cet intérêt considérable accordé à cette problématique a permis le développement d'un nombre non négligeable de modèles théoriques capables de clarifier ce prétendu lien entre les pratiques RH et la performance des organisations. Mais, selon Paauwe et Boselie ${ }^{3}$, les travaux pratiques effectués dans ce sens souffrent d'un handicape méthodologique majeure et leurs résultats restent souvent ambigus. En plus, plusieurs auteurs avaient affirmé que peu d'explications théoriques avaient été avancées pour justifier le choix des pratiques $\mathrm{RH}$ étudiées ${ }^{4}$ et qu'il est très difficile d'utiliser la connaissance acquise au fil des études du fait qu'elles émanaient d'échantillonnages distincts et intégraient des méthodes et des outils différents d'une étude à une autre pour mesurer aussi bien les pratiques RH que les différentes dimensions de la performance des organisations et loin de-là le lien de causalité entre ses deux pôles. Pour ce dernier point, en 2005, des auteurs comme Paauwe \& Boselie ${ }^{5}$ et Wright \& Haggerty 6 pensaient qu'il pouvait s'écouler deux à trois ans avant de voir apparaitre les effets d'une pratique RH introduite sur la performance des organisations et suggéraient de tenir compte de 1'aspect temporel dans les études en mesurant les différentes pratiques RH et celles de la performance dans un espace-temps distinct en vue de mieux évaluer leur relation de causalité.

\section{Role Des Pratiques RH Dans la Performance Des Organisations}

Selon Becker et Huselid ${ }^{7}$, les premières approches ayant abordé le lien susceptible d'exister entre la fonction RH et la performance des organisations, s'inséraient dans des cadres conceptuels propres aux domaines de l'économie, de la finance, de la stratégie ou de la psychologie du travail. Dans le même ordre d'idée, en 2005, Arcand et al. ${ }^{8}$ avaient répertorié quatre approches théoriques qui avaient abordé le rôle des pratiques RH dans la performance des organisations : économique, financière, stratégique et psychologique.

- L'approche économique : Dès les années soixante du siècle dernier, en prenant appui sur la théorie du capital humain, l'approche économique avait stipulé que, par analogie au capital financier ou au capital matériel, le capital humain, par l'ensemble des compétences, expériences et savoirs détenus par l'ensemble du personnel, participe à la valeur économique des organisations ${ }^{9}$.

\footnotetext{
${ }^{3}$ Paauwe J. et Boselie P. : «Human Resource Management and performance : what next? », Human Resource Management Journal, Vol. 15, N ${ }^{\circ}$, 2005 , pp. $68-83$.

${ }^{4}$ Trudel J-M., Saba T. et Guérin G. : «L'influence contrastée des pratiques de gestion des ressources humaines sur l'engagement organisationnel et la performance au travail », Revue Internationale sur le Travail et la Société, Vol. 3, 2005, pp. 406-435.

${ }^{5}$ Paauwe J. et Boselie P. : «Human Resource Management and performance : what next? », Human Resource Management Journal, Vol. 15, 으 4 , 2005, pp. 68-83.

${ }^{6}$ Wright $\mathrm{P}-\mathrm{M}$. et Haggerty J-J. : «Missing variables in theories of strategic human resource management : Time, cause, and individuals 》, Working paper series, Center for Advenced Human Resource Studies (CAHRS Working Paper \#05-03). Ithaca, NY: Cornell University, School of Industrial and Labor Relations, 2005, https://digitalcommons.ilr.cornell.edu/cahrswp/3

${ }^{7}$ Becker B. et Huselid M-A. : «High Performance Work Systems and Firm Performance : A Synthesis of Research and Managerial Implications », Research in Personnel and Human Resource Management, Vol. 16, 1998, pp. 53-101.

${ }^{8}$ Arcand G., Arcand M., Chrétien L. et Tellier G. : «Impacts des pratiques de gestion des ressources humaines sur la performance organisationnelle des entreprises de gestion de projets », Revue internationale sur le travail et la société, Vol. 3, N ${ }^{\circ} 1,2005$, pp. 107-128.

${ }^{9}$ Mc Mahan G-C., Virik M. et Wright P-M. : «Alternative theoretical perspectives for SHRM revisited : progress, problems and prospects », Research in personnel and human resources management, Supplement 4, 1999, pp. 99-122.
} 
- L'approche financière : Cette approche, qui a vu le jour pendant les années soixante-dix du siècle dernier, avance plutôt que c'est la coordination optimale entre l'ensemble du personnel qui permet de minimiser le risque d'affaire de toute organisation et delà l'atteinte du rendement visé des actifs.

- L'approche stratégique : Cette approche stipule que ce sont les variables internes créatrices de valeur difficilement imitables ou substituables (Barney ${ }^{\mathbf{1 0}}$ et Pfeffer $^{11}$ ) qui peuvent procurer un avantage concurrentiel durable et qu'une bonne part du succès des organisations dépend de la mobilisation des RH dont elles disposent.

- L'approche psychologique : En 1993, des auteurs comme Kidwell et Bennett ${ }^{12}$ avaient mis l'accent sur l'impact positif des efforts induits par les interactions soutenues entre l'ensemble du personnel sur la performance des organisations. En 1997, en prenant appui sur des aspects comme la motivation et la satisfaction, Huselid et al. ${ }^{13}$ avaient avancé que les comportements des individus induits par leur degré de motivation et de satisfaction avaient un impact non négligeable sur les résultats de toute entreprise.

En prenant appui sur les approches citées ci-dessus, d'autres approches se sont focalisées sur l'effet spécifique du seul facteur RH sur la performance des organisations. Les trois grandes approches qui ont été conçues dans ce sens ont été baptisées en 1996 par Delery et Doty ${ }^{14}$ : approche universaliste, approche de contingence et approche configurationnelle.

- L'approche universaliste : Cette approche, qui s'appuie principalement sur les études anglosaxonnes ${ }^{15}$, stipule qu'indépendamment du contexte stratégique des organisations, les pratiques RH ont un impact positif et significatif sur la performance de toute organisation. Parmi les différentes positions de la conception universaliste à savoir : l'universalisme «naturalisant», l'universalisme «des bonnes pratiques » et l'universalisme reposant sur le principe de convergence progressive des pratiques, c'est la seconde position ${ }^{\mathbf{1 6}}$ qui est la plus adoptée dans les recherches empiriques.

- L'approche de contingence : Cette approche, qui constitue une nuance à l'approche universaliste, avance que seules les pratiques $\mathrm{RH}$ compatibles avec les paramètres de la contingence de l'environnement aussi bien interne qu'externe des organisations puissent avoir un effet positif et significatif sur la performance des organisations et que les pratiques RH n'auront d'effets réels et notables sur cette dernière que si elles s'alignent sur les grandes orientations stratégiques des organisations ${ }^{17}$. L'ensemble des études qui étaient effectuées selon cette approche avaient cherché à clarifier comment les pratiques RH prises de manière individuelle arrivent à interagir avec aussi bien la stratégie organisationnelle qu'avec les évolutions de l'environnement pour permettre d'améliorer la performance des organisations ${ }^{\mathbf{1 8}}$.

\footnotetext{
${ }^{10}$ Barney J. : «Firm Resources and Sustained. Competitive Advantage », Texas A\&M University, Vol. 17, N 1, 1991, pp. 99-120.

${ }^{11}$ Pfeffer J. : «Competitive advantage through people: Unleashing the power of the work force », Boston : Harvard Business School Press, 1994.

${ }^{12}$ Kidwell R-E. et Bennett N. : «Employee propensity to withhold effort: A conceptual model to intersect three avenues of research », The Academy of Management Review, Vol. 18, N³, 1993, pp. 429-456.

${ }^{13}$ Huselid M-A., Jackson S-E. et Schuler R-S. : «Technical and strategic human resource management effectiveness as determinants of firm performance », Academy of Management Journal, Vol. 40, $N^{\circ} 1,1997$, pp. 171-188.

${ }^{14}$ Delery J-E. et Doty D-H. : «Modes of Theorizing in Strategic Human Resource Management : Test of Universalistic, Contingency, and Configurational Performance Predictions », Academy of Management Journal, Vol. 39, 1996, pp. 802-835.

${ }^{15}$ Ces études anglo-saxonnes sont relatives aux «Systèmes de travail à haute performance », comme celles de Huselid M-A. (1995) ou Pfeffer J. (1994, 1998).

${ }^{16}$ L'universalisme «des bonnes pratiques » stipule que le fait de repérer et surtout valider les meilleurs pratiques RH produira dans chaque cas un effet positif sur la performance organisationnelle.

${ }^{17}$ A ce sujet, voir les travaux de McMahan G-C. et al. en 1999 ; ceux de Wright P-M. et McMahan G-C. en 2011 ; et ceux de Way S-A. et Johnson D-E. en 2011.

${ }^{18}$ Gagnon O. et Arcand G. : «Les pratiques de GRH comme catalyseur de la performance organisationnelle », Revue internationale sur le travail et la société, Vol. 9, $\mathrm{N}^{\circ} 2,2011$, pp. 1-23.
} 
- L'approche configurationnelle: Cette approche, qui constitue une extension de l'approche contingente, stipule que la fonction RH n'a de réel effet sur la performance des organisations que si elle parvient à s'harmoniser avec les principales caractéristiques de l'organisation en regroupant de manière cohérente l'ensemble des pratiques RH. En d'autres termes le lien de causalité positive entre pratiques RH et performance des organisations est tributaire de deux conditions à savoir : l'effet de synergie entre les pratiques RH et l'interaction avec la stratégie d'affaire de l'organisation. Mais il faut signaler que ce lien de causalité doit être relativisé par rapport à la configuration, car si ce lien de causalité peut être mis en évidence dans une configuration particulière il peut ne pas être plausible dans d'autres configurations, ou même entrainer un effet inverse ${ }^{\mathbf{1 9}}$.

Partant des approches précitées plusieurs recherches empiriques avaient cherché à cerner et à éclaircir cet improbable lien entre pratiques RH et performance des organisations.

De manière générale, quelle que soit l'approche adoptée (universaliste, contingente ou configurationnelle), l'ensemble des études empiriques qui avaient cherché à cerner et à éclaircir l'impact des pratiques RH sur la performance des organisations relevaient de deux principales perspectives: unidimensionnelle ou pluridimensionnelle.

La perspective unidimensionnelle regroupe l'ensemble des études qui avaient cherché à étudier l'impact d'un type de pratique RH spécifique sur la performance des organisations ;

La perspective pluridimensionnelle englobe les études qui avaient visé à identifier les meilleures combinaisons de pratiques RH susceptibles d'influencer la performance des organisations.

Le recensement des différentes études est quasiment impossible vue leur grand nombre, mais en 2004, Allouche et al. avaient pu dresser une synthèse des résultats de 241 études empiriques et recherches effectuées entre 1978 et 2003 sur la relation des pratiques RH et les différents indicateurs de la performance des organisations. Le tableau suivant nous offre une synthèse quantitative de 235 résultats des 241 études répertoriées en 2004 par Allouche et al.

Tableau 1 : Synthèse quantitative des 235 études répertoriées en 2004 par Allouche J., Charpentier M. et Guillot-Soulez C. ${ }^{20}$.

\begin{tabular}{|c|c|c|c|c|}
\hline \multirow[t]{2}{*}{ Approches Unidimensionnelles } & Résultats & Lien positif & Lien négatif & Absence de lien \\
\hline & 133 & 80 & 37 & 16 \\
\hline Suppression d'emplois & 40 & 2 & 29 & 9 \\
\hline$\%$ & 100 & 5 & 73 & 23 \\
\hline Rémunération & 74 & 59 & 8 & 7 \\
\hline$\%$ & 100 & 80 & 11 & 9 \\
\hline Formation & 19 & 19 & 0 & 0 \\
\hline$\%$ & 100 & 100 & 0 & 0 \\
\hline \multirow[t]{2}{*}{ Approches Pluridimensionnelles : Système RH } & Résultats & Lien positif & Lien négatif & Absence de lien \\
\hline & 102 & 46 & 38 & 18 \\
\hline$\%$ & 100 & 45 & 37 & 18 \\
\hline Les 2 approches & 235 & 126 & 75 & 34 \\
\hline$\%$ & 100 & 54 & 32 & 14 \\
\hline
\end{tabular}

La juxtaposition de liens positifs et négatifs entre les pratiques de la fonction RH désignées (suppressions d'emplois, évolution des rémunérations, relations sociales) et la performance des organisations, renvoie à une forte contingence avec les conditions de mise en œuvre des actions envisagées et leur adaptation plus ou moins bonne au cadre stratégique. Donc toute forme de généralisation et d'application à une organisation

\footnotetext{
${ }^{19}$ Meyer J-P. et Herscovitch L. : «Commitment in the workplace : toward a general model », Human Resource Management Review, Vol. 11, 2001, pp. 299-326.

${ }^{20}$ Allouche J., Charpentier M. et Guillot-Soulez C. : «GRH et Performances de l'entreprise : l'improbable lien ? Un panorama des études académiques sur l'interaction performances sociales/performances économiques et financières ", XVe Congrès annuel de l'AGRH, Montréal, tome 1, 2004, pp. 31-58.
} 
donnée ne peut être pertinente à coup sûr ${ }^{21}$.

\section{Confirmation Empirique Du Lien Pratiques RH Et Performance Des Organisations Depuis 2004}

\section{Les études menées en 2004}

L'étude de Bartel ${ }^{22}$, qui était effectuée auprès de 228 salariés de trois organisations de services financiers irlandaises, avait montré que les effets d'interaction sont évidents en ce qui concerne les attitudes des salariés envers les pratiques RH et l'engagement affectif, continu et normatif. Mais il est possible que les organisations cherchant à promouvoir l'engagement de leurs employés aient besoin d'adapter les pratiques RH aux besoins des employés, remettant ainsi en question la perspective des meilleures pratiques RH au niveau des employés.

* L'étude de Bowen et Ostroff ${ }^{23}$ avait analysé les méta-fonctionnalités des systèmes RH qui se traduisaient par un climat organisationnel dans lequel les salariés partageaient une interprétation commune des comportements attendus et récompensés. Les résultats de cette étude avaient stipulé que les systèmes de travail à haute performance entrainaient une forte agrégation des attributs individuels des employés et par la suite affectaient de manière positive l'efficacité organisationnelle. L'étude de Carriere et Barrette ${ }^{24}$, qui était effectuée auprès de 175 firmes à capital intellectuel élevé, avait indiqué que l'index de configuration des pratiques RH (degré de complémentarité) apportait généralement une augmentation de la prédiction de la performance organisationnelle en supplément de celle prédite par l'index de contingence (degré d'apprentissage organisationnel) et que ce dernier apportait à son tour partiellement une augmentation de la prédiction de la performance organisationnelle en supplément de celle prédite par le précédent.

L'étude de Chrétien et al. ${ }^{25}$, qui avait été effectuée auprès de 48 entreprises de gestion de projet situées au Québec et œuvrant dans le domaine du génie conseil, avait, à l'exception de l'évaluation $\mathrm{du}$ rendement, soutenu que toutes les autres pratiques $\mathrm{RH}^{26}$ lorsqu'elles étaient appliquées en contexte de gestion de projet impliquaient des résultats significatifs.

L'étude de Colvin et al. ${ }^{27}$, qui était menée aux USA auprès d'un échantillon représentatif d'établissements du secteur des télécommunications, avait montré que les taux d'absentéisme, de

\footnotetext{
${ }^{21}$ Reprenons les propos d'Allouche J., Charpentier M. et Guillot-Soulez C. qui stipulaient en 2004 dans « GRH et Performances de l'entreprise : l'improbable lien? Un panorama des études académiques sur l'interaction performances sociales/performances économiques et financières ", XVe Congrès annuel de l'AGRH, Montréal, tome 1, 2004, pp. 31-58, que : "Ces résultats doivent cependant être interprétés au regard des différents thèmes étudiés : les relations positives sont en effet dues en majorité à des pratiques RH ayant pour objectif le développement des RH dans l'entreprise (rémunération, formation) alors que les résultats négatifs sont davantage liés aux pratiques d'ajustement de l'emploi et aux conséquences des relations sociales. Il convient toutefois de noter que, au sein des différents types de performances étudiées, les effets des pratiques RH sur la performance organisationnelle (commerciale et productive) sont plus souvent positifs que dans le cas de la performance financière ou boursière laissant entrevoir un lien plus direct entre les pratique RH et la performance organisationnelle qu'entres les pratiques RH et la performance financière ou boursière ».

${ }^{22}$ Bartel A. : «Relating career stage to attitudes towards HR practices and commitment : Evidence of interaction effects ? », European Journal of Work and Organizational Psychology, Vol. 13, N 4, 2004, pp. 417-446.

${ }^{23}$ Bowen D-E. et Ostroff C. : "Understanding HRM-Firm Performance Linkages: The Role of the "Strength" of the HRM System », The Academy of Management Review, Vol. 29, $\mathrm{N}^{\circ}$ 2, April 2004, pp. 203-221.

${ }^{24}$ Carriere J. et Barrette J. : «GRH et performance de la firme à capital intellectuel élevé : une application des perspectives de contingence et de configuration », Canadian Journal of Administrative Sciences, Vol. 22, $\mathrm{N}^{\circ}$ 4, pp. 302-315.

${ }^{25}$ Chrétien L., Arcand G., Tellier G. et Arcand M. : «Impacts des pratiques de GRH sur la performance organisationnelle des entreprises de gestion de projets », Revue Internationale sur le Travail et la Société, Vol. 3, $\mathrm{N}^{\circ}$ 1, 2005, pp. 107-126.

${ }_{26}^{26}$ Les pratique RH qui étaient retenues dans cette étude sont : l'analyse des emplois, la planification RH, la planification des carrières, la sélection, l'accueil, l'évaluation du rendement, la rémunération incitative et la formation.

${ }^{27}$ Colvin A., Batt R. et Keefe J. : "The Impact of Employee Voice and Compliance Mechanisms on Absenteeism, Discipline, and Turnover ", CAHRS Working Paper, Ithaca, NY : Cornell University, School of Industrial and Labor Relations, Center of Advanced Human Resource Studies, 2005, http://digitalcommons.ilr.cornel.edu/cahrswp/281/
} 
départs et de congédiements considérablement réduits étaient associés aux mécanismes de représentation des salariés sous forme d'unions ou de groupes de résolution de problèmes. En revanche, les mécanismes de conformité des règles de travail strictes étaient associés à des taux plus élevé aussi bien de discipline que de licenciement.

* L'étude de Datta et al. ${ }^{28}$, qui était effectuée aux USA auprès de 971 entreprises, avait indiqué que l'intensité du capital de l'industrie, le taux de croissance et la politique de différenciation jouaient un rôle déterminant dans l'explication de l'impact des systèmes de travail à haute performance sur la productivité et delà sur la performance des organisations.

* L'étude de D'Art et Turner ${ }^{29}$, qui était effectuée auprès de 2827 entreprises réparties sur 11 pays européens, n'avait pu confirmer la relation significative et positive entre les pratiques de partage de profit et la performance financière qu'uniquement dans deux pays parmi les 11 étudiés, ce qui ne permettait pas aux chercheurs de conclure à l'existence d'une association positive entre les pratiques de partage de profits et la performance financière.

L'étude de Fabi et al. ${ }^{30}$, qui était menée auprès d'un échantillon de 350 PME manufacturières québécoises, avait attesté que les pratiques de participation aux décisions, de formation, de diffusion d'informations stratégiques et de description des tâches étaient positivement associées à la performance des PME. Mais la simple application de ces pratiques RH ne suffisait pas et ce serait plutôt l'intensité avec laquelle on les avait appliqué qui faisait la différence.

* L'étude de Guerrero et Barraud-Didier ${ }^{31}$, qui était effectuée auprès de 180 responsables RH de grandes entreprises françaises, avait montré que lorsque les 4 pratiques RH spécifiques retenues dans cette étude ${ }^{32}$ étaient combinées en un faisceau produisaient un impact plus fort sur la performance que lorsqu'elles étaient étudiées isolément.

* L'étude de Lacoursière et al. ${ }^{33}$, qui était effectuée auprès de 233 PME manufacturières québécoises, avait attesté que les pratiques RH relatives à la diffusion d'information présentaient des corrélations significatives avec le taux de départs volontaires des employés, les pratiques RH concernant la formation et la participation à la prise de décision présentaient des corrélations significatives avec la productivité du personnel de production. En plus, les cinq pratiques RH suivantes : pratiques de descriptions de taches, de recrutement, de l'évaluation du rendement, de diffusion des résultats de productivité et de participation aux décisions, présentaient des corrélations significatives avec la croissance de ventes des cinq dernières années. Enfin, deux pratiques RH à savoir : pratiques de descriptions de taches et celle de diffusion d'informations relatives aux états financiers, présentaient des corrélations significatives avec le taux de rendement de l'actif.

L'étude de Paul et Anantharaman ${ }^{34}$, avait révélé qu'en Inde les pratiques RH telles que l'environnement de travail convivial, le développement de carrière, l'évaluation axée sur le développement et les plans de formation avaient une relation positive significative avec l'engagement organisationnel. En plus cette étude avait montré que des pratiques RH similaires

${ }^{28}$ Datta D-K., Guthrie J-P. et Wright P. : «HRM and Labor Productivity : Does Industry Matter ? », The Academy of Management Journal, Vol. 48, $\mathrm{N}^{\circ} 1$, February 2005. https://doi.org/10.5465/amj.2005.15993158

${ }^{29}$ D'art D. et Turner T. : «Profit sharing, firm performance and union influence in selected European countries », Personnel Review, Vol. $33, \mathrm{~N}^{\circ}$ 3, 2004, pp. 335-350.

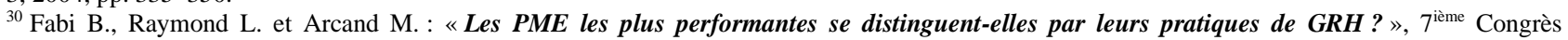
International Francophone en Entrepreneuriat et PME, Octobre 2004, Montpellier.

${ }^{31}$ Guerrero S. et Barraud-Didier V. : «High-involvement practices and performance of French firms », The International Journal of Human Resource Management, Vol. 15, N 8, 2004, pp. 1410-1425.

${ }^{32}$ Les 4 pratiques RH spécifiques capables d'impliquer les salariés retenues dans cette étude sont: l'autonomisation, la compensation, la communication et la formation.

${ }^{33}$ Lacoursière R., Fabi B., St-Pierre J. et Arcand M. : «Effets de certaines pratiques de GRH sur la performance de PME manufacturières : vérification de l'approche universaliste » Revue internationale P.M.E., Vol. 18, $\mathrm{N}^{\circ}$ 2, 2005, pp. 43-75.

${ }^{34}$ Paul A-K. et Anantharaman R-N. : «Influence of HRM practices on organizational commitment : A study among software professionals in India », Human Resource Development Quarterly, Vol. 15, $\mathrm{N}^{\circ} 1$, February 2004, pp. 77-88. 
entraînent plus d'engagement organisationnel en Inde qu'en Suisse.

L'étude de $\operatorname{Raad}^{35}$ qui était menée auprès d'un échantillon d'entreprises ayant mis en place un dispositif d'actionnariat salarial, avait confirmé que l'actionnariat des salariés était une pratique sociale contribuant par ses effets à l'amélioration de la performance des organisations. Toutefois, ce dispositif, isolé d'un système de pratiques RH cohérentes, n'aurait pas d'effets considérables sur la performance des dites entreprises.

L'étude de Wright et al. ${ }^{36}$, à l'aide de données provenant de 45 unités commerciales opérantes aux USA et au Canada, avait examiné comment les pratiques RH sont en corrélation avec les performances opérationnelle passées, actuelles et futures. Les résultats avaient indiqué que les corrélations avec les performances aux 3 temps étaient à la fois élevées et invariantes, et que le contrôle des performances passées ou simultanées éliminait pratiquement la corrélation des pratiques $\mathrm{RH}$ avec les performances futures.

\section{Les études menées en $\mathbf{2 0 0 5}$}

L'étude d'Aït Razouk A. ${ }^{37}$, qui était effectuée auprès de 2930 établissements français de plus de 20 salariés, avait montré que les systèmes RH lorsqu'ils étaient en cohérence avec la stratégie organisationnelle influaient les quatre dimensions suivantes de la performance des organisations : la rentabilité, l'innovation, l'absentéisme et le climat social.

* L'étude Khandekar et Sharma ${ }^{38}$, qui était effectué auprès de 300 responsables RH de neuf sociétés mondiales indiennes et étrangères de New Delhi, avait révélé que les capacités des RH étaient positivement corrélées à la performance organisationnelle et qu'elles constituaient un indicateur important de l'avantage concurrentiel durable.

* L'étude de Payne et Huffman ${ }^{39}$, effectué auprès de plus de 1000 officiers de l'armée américaine, avait indiqué que le mentorat était positivement lié à l'engagement affectif et à l'engagement de continuation et négativement lié au « comportement de rotation ». Selon toujours cette étude, la relation avec l'engagement affectif a été modérée par les conditions du mentorat (superviseur versus non supervisé) mais pas par le type de soutien au mentorat fourni (lié à la carrière versus psychosocial).

L'étude de Trudel et al. ${ }^{40}$, qui était réalisée auprès de 980 cadres du domaine de la santé et des services sociaux du Québec, avait révélé que les pratiques RH issues d'une stratégie de valeur ajoutée influençaient de façon plus significative les trois composantes de l'engagement organisationnel et la performance au travail. À l'opposé, les pratiques RH issues d'une stratégie de réduction des coûts avaient une influence faible sur les mêmes variables.

\section{Les études menées en 2006}

\footnotetext{
${ }^{35}$ Raad G. : «L'influence de l'implication organisationnelle sur l'intention d'adhésion à l'actionnariat salarié », Thèse de doctorat en Sciences de gestion soutenue en 2006 à Caen.

${ }^{36}$ Wright P-M., Gardner T-M., Moynihan L-M. et Allen M-R. : "The relationship between HR practices and firm performance : Examining causal order $»$, Personnel Psychologie, Vol 58, $\mathrm{N}^{\circ} 2,2005$, pp. 409-446.

${ }^{37}$ Aït Razouk A. : «GSRH : recherche théorique et empirique sur la durabilité de la relation entre stratégie RH et performance », Thèse soutenue en 2007 à Nancy 2.

${ }^{38}$ Khandekar A. et Sharma A. : «Managing human resource capabilities for sustainable competitive advantage: An empirical analysis from Indian global organisations », Education and Training, Vol. 47, $\mathrm{N}^{\circ}$ 8/9, October 2005, pp. 628-639.

${ }^{39}$ Payan S-C. et Huffman A-H. : «A Longitudinal Examination of the Influence of Mentoring on Organizational Commitment and Turnover », The Academy of Management Journal, Vol. 48, No 1, February 2005, pp. 158-168.

${ }^{40}$ Trudel J-M., Saba T. et Guérin G. : «L'influence contrastée des pratiques de gestion des ressources humaines sur l'engagement organisationnel et la performance au travail », Pratiques, Vol. 1, $\mathrm{N}^{\circ} 25,2005$, pp. 1705-6616.
} 
L'étude de Cho et al. ${ }^{41}$ avait pour objectif d'analyser la relation entre les pratiques $\mathrm{RH}$ et la performance organisationnelle ${ }^{42}$. Les résultats avaient indiqué que les pratiques $\mathrm{RH}$ retenues avaient une relation significative avec le taux de rotation des employés non dirigeants et qu'aucune preuve significative n'a été trouvée concernant l'impact des dites pratiques RH sur les autres mesures retenues de la performance organisationnelle.

L'étude de Chourouk $^{43}$, qui était effectuée auprès de 221 PME manufacturières québécoises, avait montré que les trois pratiques de rémunération variable retenues ${ }^{44}$ amélioraient la performance financière mais uniquement par l'intermédiaire de la performance organisationnelle.

L'étude de Combs et al. ${ }^{45}$, qui est une agrégation statistique de 92 études sur les pratiques RH à haut potentiel et la performance des organisations, avait, en dehors du fait que la variation des caractéristiques des échantillons, des plans de recherche, des pratiques examinées et des mesures du rendement organisationnel utilisées affectent les résultats obtenus, révélé une corrélation globale estimée à 0,20 et que les effets sont plus importants pour les systèmes de pratiques RH à haute performance par rapport aux pratiques individuelles. mais elle semble invariante dans les mesures de performance.

L'étude de Daud et al. ${ }^{46}$, qui était menée auprès de 162 gestionnaires des RH des entreprises manufacturières malaisiennes, avait indiqué que :

$\checkmark$ L'impact de la planification des RH sur la rentabilité et la croissance était modéré respectivement par le degré d'incertitude de l'environnement et par la stratégie commerciale ;

$\checkmark$ La rémunération basée sur le rendement et le développement des compétences avaient une relation avec le turnover des employés.

L'étude de Green et al. ${ }^{47}$, qui était effectuée auprès de 269 professionnels des RH provenant de grandes entreprises manufacturières américaines, avait révélé l'existence d'un impact positif significatif de la gestion stratégique des RH sur la performance organisationnelle et ceci par un fort engagement organisationnel et une grande satisfaction au travail.

L'étude de Lambooij et al. ${ }^{48}$, qui était menée auprès de 723 salariés de dix organisations, avait constaté que la coopération avec les collègues était liée négativement au roulement du personnel et positivement liée aux congés de maladie, mais malheureusement les résultats n'avaient pas pu montrer que les pratiques RH alignées entre elles (Ajustement interne) et alignées avec la stratégie de l'organisation (Ajustement stratégique) conduisaient à un comportement plus coopératif de la part des employés.

\section{Les études menées en 2007}

\footnotetext{
${ }^{41}$ Cho S., Woods R-H., Jang S-C. et Erdem M. : «Measuring the impact of human resource management practices on hospitality firms' performances », International Journal of Hospitality Management, Vol. 25, $\mathrm{N}^{\circ}$ 2, 2006, pp. 262-277.

${ }^{42}$ Dans cette étude la performance organisationnelle a été mesurée par les taux de rotation des employés de gestion non-dirigeants, la productivité du travail et le rendement des actifs.

${ }^{43}$ Chourouk S-M. : "Impacts des pratiques de rémunérations variables sur la performance organisationnelle et financière de certaines PME manufacturières », Mémoire, Université du Québec à Trois-Rivières, Septembre 2006.

${ }^{44}$ Le chercheur a retenu trois pratiques : les pratiques de rémunération incitative avec prime et bonus, les pratiques de partage des profits et les pratiques d'accès à la propriété.

${ }^{45}$ Combs J-G., Liu Y., Hall A. et Ketchen D. : «How Much Do High-Performance Work Practices Matter ? A Meta-Analysis of Their Effects on Organizational Performance », Personnel Psychology, Vol. 59, 우 3, August 2006, pp. 501-728. https://doi.org/10.1111/j.1744-6570.2006.00045.x ${ }^{46}$ Daud S., Abidin N., Sapuan N-M. et Rajadurai J. : «Efficient human resource deployment technique in higher education: A standpoint from Malaysia », African Journal of Business Management, Vol. 6, N²5, June 2012, pp. 7533-7547.

${ }^{47}$ Green K-W., Wu C., Whitten D. et Medlin B. : «The impact of SHRM on firm performance and HR professionals work attitude and work performance », The International Journal of Human Resource Management, Vol. 17, $\mathrm{N}^{\circ}$ 4, 2006, pp. 559-578.

${ }^{48}$ Lambooij M., Sanders K., Ferry K. et Zwiers M. : «Human Resource Practices and Organisational Performance : Can the HRM-Performance linkage be explained by the cooperative Behaviours of Employees? », Management Revue, Socio-economic Studies, Vol. 17, № 3, 2006, pp. 223240.
} 
L'étude d'Al-Emadi et Marquardt ${ }^{49}$, qui était menée auprès de 283 cadres nationaux qatariens de Qatar Petroleum avait confirmé l'existence d'une relation positive entre les croyances des employés concernant les avantages de la formation continue et leur engagement organisationnel.

* L'étude de Cassoni et al. ${ }^{50}$, qui était menée auprès de 274 moyennes et grandes entreprises uruguayennes, avait montré que les pratiques RH avaient un impact marginal sur la performance, en fonction de leur nature calculatrice ou collaborative et surtout que leur effet pouvait être positif ou négatif en termes de complémentarités différentes entre les pratiques et selon la dimension de performance considérée.

* L'étude de Charles-Pauvers et al. ${ }^{51}$, qui était menée auprès de 59 salariés des centres d'appel français, avait relevé une corrélation significative négative entre la $\mathrm{DMT}^{52}$ et la satisfaction vis-à-vis de la rémunération globale et l'implication affective. En plus, cette étude avait montré que les téléconseillers qui étaient accompagnés réussissaient à vendre avec succès par rapport à ceux qui percevaient le style de management comme «absent» (non compétence ou manque d'intérêt des supérieurs).

* L'étude de Colot et al. ${ }^{53}$, qui était menée auprès de 60 grandes entreprises familiales belges, avait montré que dans un contexte familial le travail à temps partiel augmente significativement le taux de rotation pendant que le taux de formation le réduit. En plus, à la différence du contexte non familial où ce sont les rémunérations, la formation, l'âge de l'entreprise, les secteurs des services ou de la construction qui affectaient significativement la rotation du personnel, seul le secteur commercial influençaient significativement le taux de rotation dans un contexte exclusivement familial.

* L'étude de Fiorito et al. ${ }^{54}$, qui avait utilisé des données recueillies auprès du National Organizations Survey (NOS), avait montré que les mécanismes de règlement des griefs et les indicateurs d'implication des employés sont positivement liés à l'engagement organisationnel et que les réductions de rémunération sont négativement liées à l'engagement organisationnel. Mais ce qu'il faut retenir de cette étude c'est que la plupart des mesures des pratiques RH n'étaient pas des prédicteurs significatifs de l'engagement organisationnel.

L'étude de Pare et Tremblay ${ }^{55}$, qui avait porté sur 394 salarié canadiens, avait révélé que la reconnaissance non monétaire et le développement des compétences et, dans une moindre mesure, des récompenses équitables et des pratiques de partage d'informations, étaient liés de manière négative et directe aux intentions de roulement. Les auteurs avaient également observé que la justice procédurale, l'engagement affectif et de continuation et les comportements de citoyenneté atténuaient en partie les effets des pratiques RH à forte implication sur les intentions de roulement de professionnels hautement qualifiés.

\footnotetext{
${ }^{49}$ Al-Emadi M-A-S. et Marquardt M-J. : «Relationship between employees' beliefs regarding training benefits and employees' organizational commitment in a petroleum company in the State of Qatar », International Journal of Training and Development, Vol. 11, № 1, February 2007, pp. 49-60.

${ }^{50}$ Cassoni A. et Labadie G-J. : «The impact of HRP and labor relations on organizational performance in Uruguay : an empirical test», Document de recherche, No 83, Décembre 2012, Universidad ORT Uruguay, Faculté d'Administration et des Sciences Sociales.

${ }^{51}$ Charles-Pauvers B., Urbain C. et Le Quentrec : «Pratiques De GRH Et Performance Commerciale : Le cas d'un centre d'appels », Revue française de gestion, $\mathrm{N}^{\circ} 176,2007$, pp. 15-33.

${ }^{52}$ Durée Moyenne de Traitement : L'un des indicateurs de mesure de la productivité pour les Centres d'appel.

${ }^{53}$ Colot O., Dupont C. et Volral M. : «Influence des pratiques de GRH sur la performance sociale des entreprises familiales », $2^{\mathrm{i} e ̀ m e s}$ journées Georges Doriot, 15 et 16 Mai 2008.

${ }^{54}$ Fiorito J., Bozeman D-P., Young A. et Meurs J-A. : «Organizational commitment, human resource practices, and organizational characteristics », Journal of Managerial Issues, Vol. 19, $\mathrm{N}^{\circ}$ 2, 2007, pp. 186-207.

${ }^{55}$ Pare G. et Tremblay M. : «The Influence of High-Involvement Human Resources Practices, Procedural Justice, Organizational Commitment, and Citizenship Behaviors on Information Technology Professionals' Turnover Intentions »; Group et Organization Management, Vol. 32, № 3 , June 2007, pp. 326-357.
} 
L'étude de Sun et al. ${ }^{56}$, qui était effectuée auprès d'un échantillon de salariés chinois travaillant dans les hôtels, avait révélé que le comportement citoyen organisationnel axé sur le service médiatisait en partie les relations entre les pratiques $\mathrm{RH}$ à haute performance et les deux indicateurs de performance retenus à savoir la productivité et le turnover.

\section{Les études menées en 2008}

* L'étude de Chew et $\mathrm{Chan}^{57}$, qui s'était déroulée en trois phases ${ }^{58}$, avait montré que l'engagement organisationnel des employés permanents et leur intention de rester étaient étroitement liée à l'adéquation poste-individu, à la rémunération, à la reconnaissance, à la formation et au développement de carrière. Mais étonnamment, la formation et le développement de carrière n'étaient pas significativement liés à l'engagement organisationnel et les affectations difficiles n'étaient pas significativement liées à l'intention de rester.

L'étude de Giauque et al..$^{59}$, qui était menée au sein de quelques organisations publiques de Suisse romande, avait mis en évidence l'importance de facteurs tels que l'ambiance de travail, le degré de transparence, d'autonomie et de conduite participative dans le développement d'un sentiment d'efficacité auprès des collectifs de travail et salariés du secteur public Suisse romande ainsi que l'importance centrale du pilotage « participatif» surtout celui qui était centré sur les valeurs.

* L'étude de Hunter et al..$^{60}$, qui avait analysé quatre-vingt-dix-sept cas de turn-over (42 à Singapour et 55 en Nouvelle-Zélande), avait indiqué qu'à côté des facteurs de roulement universels culturellement indépendants, il existait des facteurs sensibles à la culture qui devraient être pris en compte par les gestionnaires lorsqu'ils traitaient avec une main-d'œuvre internationale.

* L'étude de Katou ${ }^{61}$, qui était effectuée auprès de 178 organisations manufacturières grecques, avait indiqué que la relation entre les politiques RH (Ressources et Développement, Rémunération et Incitations, Implication et Conception des Emplois) et la performance des organisations était en partie médiée par les résultats de la fonction RH (Compétences, Attitudes et Comportements), et qu'elle était influencée par les stratégies commerciales (Coût, Qualité et Innovation).

* L'étude de Luna-Arocas et Camps ${ }^{62}$, qui était effectuée auprès de 198 employés, avait montré l'impact positif des stratégies de rémunération et d'enrichissement de l'emploi sur la satisfaction au travail qui affectait à son tour les intentions de roulement des salariés et que cette dernière relation était médiée par l'engagement des employés.

L'étude d'Ordonez de Pablos et Lytras ${ }^{63}$, qui est une étude documentaire, avait attesté que la performance de la fonction RH était tributaire de l'adoption de technologies d'apprentissage améliorées et de technologies sémantiques du Web qui pouvaient guider les stratégies de gestion

\footnotetext{
${ }^{56}$ Sun L-Y., Aryee S. et Law K-S. : «High-performance human resource practices, citizenship behavior, and organizational performance : A relational perspective », Academy of Management Journal, Vol. 50, N3, 2007, pp. 558-577.

${ }^{57}$ Chew J. et Chan C-C-A. : «Human resource practices, organizational commitment and intention to stay », International Journal of Manpowr, Vol. 29, $\mathrm{N}^{\circ} 6,2008$, pp. 503-522.

${ }^{58}$ Premièrement, 13 experts (par exemple, des universitaires, des responsables RH et des psychologues organisationnels) avaient été interrogés à l'aide de la technique Delphi. Deuxièmement, des entretiens approfondis avec 12 responsables RH avaient été menés. Troisièmement, 457 employés de neuf organisations australiennes avaient répondu à l'enquête.

${ }^{59}$ Giauque D., Barbey V. et Duc N. : «Les leviers de la performance individuelle et collective dans les organisations publiques suisses : l'importance d'un pilotage participatif », Revue française d'administration publique, Vol. 4, 2008, pp. 785-798.

${ }^{60}$ Hunter M-G., Tan F-B. et Tan B-C. : «Voluntary turnover of information systems professionals : A cross-cultural investigation », Journal of Global Information Management, Vol. 16, $\mathrm{N}^{\circ}$ 4, 2008, pp. 46-66.

${ }^{61}$ Katou A-A. : «Measuring the impact of HRM on organisational performance », Journal of Industrial Engineering and Management, Vol. 1, $\mathrm{N}^{\circ}$ 2, 2008, p. 119-142.

${ }^{62}$ Luna-Arocas R. et Camps J. : «A model of high performance work practices and turnover intentions », Personnel Review, Vol. 37, $\mathrm{N}^{\circ} 1,2008$, pp. $26-46$.

${ }_{63}$ Ordonez de Pablos P. et Lytras M. : «Competencies and human resource management: implications for organizational competitive advantage »? Journal of Knowledge Management, Vol. 12, $\mathrm{N}^{\circ}$ 6, October 2008, pp. 48-55.
} 
efficace des compétences dans les organisations modernes et delà améliorer leur performance.

L'étude de Vlachos $^{64}$, qui était menée auprès de responsables du secteur de l'alimentation grecque, avait révélé que l'embauche sélective était une pratique clé pour améliorer la performance organisationnelle et que la politique de rémunération, le partage d'informations, la décentralisation de la prise de décision étaient des prédicteurs significatifs pour toutes les variables de performance.

L'étude de Wright et Kehoe ${ }^{65}$, qui avait examiné les nouvelles conceptualisations des pratiques RH dans la relation RH-performance ainsi que les nouvelles conceptualisations de l'engagement, avait montré que la juxtaposition de ces catégories de pratiques RH et les types d'engagement fournissait un rationnel théorique plus clair pour au moins certaines façons dont les pratiques RH pouvaient influencer la performance organisationnelle, qu'elle soit de manière positive ou négative.

\section{Les études menées en 2009}

L'étude de Gellatly et al. ${ }^{66}$, qui était effectuée auprès de 317 répondants travaillant dans diverses organisations canadiennes, avait montré que les perceptions des employés des pratiques RH axées sur le développement, la stabilité et la récompense affectaient la probabilité d'engagement aussi bien affectif que continu.

L'étude de Kuvass et Dysvik ${ }^{67}$, qui était constitué de trois enquêtes transversales auprès d'un total de 826 salariés d'organisations situées en Norvège, avait montré que la motivation intrinsèque jouait un rôle médiateur dans la relation entre l'investissement perçu dans le développement des employés et l'effort de travail et un rôle modérateur dans la relation entre l'investissement perçu dans le développement des employés et le comportement de citoyenneté organisationnelle.

L'étude de Moideenkutty et al. ${ }^{68}$, qui avait porté sur 87 sociétés cotées sur le marché des valeurs mobilières de Muscat au Sultanat d'Oman, avait montré que les entreprises ayant manifesté une forte implication des RH avaient une performance organisationnelle très élevée aussi bien subjective (Performance sociale) qu'objective (Ratio : Valeur de marché / Valeur comptable).

\section{Les études menées en 2010}

L'étude de Collings et al. ${ }^{69}$, qui était effectuée auprès de 340 entreprises en Turquie, avait attesté que seul l'alignement stratégique des pratiques RH était capable d'influencer positivement les trois résultats organisationnels suivants : les compétences et capacités des employés, la motivation des employés et la performance financière des entreprises étudiées.

- L'étude de Giauque et al. ${ }^{70}$, qui était effectuée auprès de 198 travailleurs du savoir, avait montré que le soutien organisationnel, la justice procédurale et la réputation de l'organisation influençaient

\footnotetext{
${ }^{64}$ Vlachos L. : «The effect of human resource practices on organizational performance : Evidence from Greece », The International Journal of Human Resource Management, Vol. 19, N 1, 2008, pp. 74-97.

${ }^{65}$ Wright $\mathrm{P}-\mathrm{M}$. et Kehoe R-R. : «Human resource practices and organizational commitment : A deeper examination », Asia Pacific Journal of Human Resources, Vol.46, $\mathrm{N}^{\circ}$ 1, 2008, pp. 6-20.

${ }^{66}$ Gellatly I-R., Hunter K-H., Currie L. et Irving P-G. : «HRM practices and organizational commitment profiles », The International Journal of Human Resource Management, Vol. 20, № 4, 2009.

${ }^{67}$ Kuvass B. et Dysvik A. : "Perceived investment in employee development, intrinsic motivation and work performance », Human Resource Management Journal, Vol. 19, $\mathrm{N}^{\circ}$ 3, 2009, pp. 217-236.

${ }^{68}$ Moideenkutty U., Al-Lamki A. et Murthy Y-S-R. : «HRM practices and organizational performance in Oman », Personnel Review, Vol. 40, ${ }^{\circ}$ 2, February 2011, pp. 239-251.

${ }^{69}$ Collings D-G., Demirbag M., Mellahi K. et Tatoglu E. : «Strategic orientation, human resource management practices and organizational outcomes : Evidence from Turkey », The International Journal of Human Resource Management, Vol. 21, ํ 14, November 2010, pp. $2589-2613$.

${ }^{70}$ Giauque D., Resenterra F. et Siggen M. : «The relationship between HRM practices and organizational commitment of knowledge workers. Facts obtained from Swiss SMEs », Human Resource Development International, Vol. 13, 으 2, 2010, pp. 185-205.
} 
l'engagement des travailleurs du savoir, alors que l'implication dans la prise de décision, la gestion des compétences ou même le degré de satisfaction à l'égard de la rémunération ne le faisaient pas.

L'étude de Nemli Çaliskan ${ }^{71}$, qui avait essayé de déterminer l'impact des pratiques stratégique RH sur la performance des entreprises turques, avait montré que les gestionnaires qui avaient conçu et mettaient en place des systèmes cohérents de pratiques RH obtenaient de meilleurs résultats opérationnels pour enfin atteindre une performance organisationnelle plus élevée.

* L'étude d'Omri et Ghorbel-Zouari ${ }^{72}$, qui avait cherché à évaluer la performance sociale dans les IMF73 tunisiennes, avait montré que les bons résultats qui étaient réalisés par les institutions objets de l'étude étaient dû en grande partie à leur politique RH favorisaient l'épanouissement, la motivation, le développement des compétences et le sentiment d'appartenance.

* L'étude de Pati et al. ${ }^{74}$, qui voulait clarifier comment les pratiques RH pouvaient façonner et induire des attitudes au travail capables d'améliorer la performance des organisations commerciales indiennes, avait montré les attitudes de travail comme : l'estime de soi organisationnelle et la participation au travail étaient souhaitables pour améliorer la performance et que la sélection, la promotion interne, l'implication dans la prise de décision et les équipes de travail autonomes étaient largement utilisables pour susciter la manifestation des dites attitudes de travail.

Reiche et al. ${ }^{75}$, qui avaient cherché, dans leur éditorial, à refléter les perspectives des études de la culture à différents niveaux d'analyse : individuel, collectif et organisationnel, avaient reconnu que la partition de la recherche culturelle en différents niveaux peut générer des images partiellement vraies mais incomplètes des interdépendances complexes qui façonnent la culture et exercent leur influence sur le comportement des acteurs sociaux.

\section{Les études menées en 2011}

L'étude d'Aït Razouk et Bayad ${ }^{76}$, qui était effectuée auprès de 275 PME françaises, avait examiné le lien entre les pratiques mobilisatrices des $\mathrm{RH}^{77}$ et la performance des $\mathrm{PME}$ françaises ${ }^{78}$. En testant la causalité inversée et en procédant au contrôle de l'effet de la performance passée, les chercheurs n'avaient pas pu confirmer l'effritement des associations constatées entre l'indice des pratiques mobilisatrices et les indicateurs de rentabilité et de climat social actuels.

* L'étude de AL Damoe et al. ${ }^{79}$, qui s'était penchée sur l'effet médiateur des résultats de la fonction $\mathrm{RH}$ dans la relation entre les pratiques RH et la performance organisationnelle, avait conclu que seule la rétention des employés est susceptible de servir de médiateur dans la relation entre les pratiques $\mathrm{RH}$ et la performance organisationnelle.

L'étude de Gagnon et Arcand ${ }^{80}$, qui s'était interrogée sur l'effet de l'alignement des pratiques RH à

\footnotetext{
${ }^{71}$ Nemli Çaliskan E. : «The Impact Of SHRM On Organizational Performance », Journal of Naval Science and Engineering, Vol. 6, N ${ }^{\circ} 2,2010$, pp. 100-116.

${ }^{72}$ Omri W. et Ghorbel-Zouari S. : Une évaluation de la performance sociale des IMF Tunisiennes : Cas de ENDA inter-arabe», Revue Libanaise de Gestion et d’Economie, $N^{\circ}$ 4, 2010, pp. 36-64.

${ }^{73}$ Institutions de Microfinances

${ }^{74}$ Pati S-P. et Kumar M-P-P. : «Influencing employee attitudes through HR practices: an exploratory study in Indian IT sector », International Journal of Indian Culture and Business Management, Jan 2010, Vol. 3, № 6, pp. 607-622

${ }^{75}$ Reiche B-S., Carr C. et Pudelko M. : «The Role Of Culture At Different Levels Of Analysis», International Journal Of Cross Cultural Management, Vol. 10, $\mathrm{N}^{\circ} 2,2010$, pp ; 131-136.

${ }^{76}$ Ait Razouk A. et Bayad M. : «GRH mobilisatrice et performance des PME : quelle causalité ? », Revue de GRH, Vol. 4, № 82, 2011 , pp. 3-18.

${ }^{77}$ Les pratiques mobilisatrices étaient conçues comme un ensemble de pratiques complémentaires des RH mesuré sous forme d'un indice additif et non comme des pratiques individuelles.

${ }^{78}$ La performance était étudiée à travers son caractère multidimensionnel et mesurée par l'intermédiaire de la rentabilité et le climat social.

${ }^{79}$ ALDamoe F-M-A., Yazam M. et Bin Ahmid K. : «The Mediating Effect of HRM Outcomes (employee retention) on the Relationship between HRM Practices and Organizational Performance », International Journal of Human Resource Studies, Vol. 2, N 1, pp. 75-88.

${ }^{80}$ Gagnon O. et Arcand G. : «Les Pratiques de GRH Comme catalyseur de la performance organisationnelle », Revue Internationale sur le Travail et la Société, Vol. 9, $\mathrm{N}^{\circ} 2,2011$, pp. 1-23.
} 
la stratégie d'affaires dans une entreprise manufacturière québécoise, avait montré que le manque de planification stratégique et le peu de partage de la vision organisationnelle provoquait des carences quant à la définition des objectifs et des pratiques de gestion à mettre en place ce qui sous-tendait un manque de performance organisationnelle.

L'étude de Hounkou ${ }^{81}$, qui avait comme but de vérifier pour les entreprises béninoises les éventuelles corrélations entre plusieurs pratiques de la fonction RH et plusieurs indicateurs de performance, avait montré qu'il était possible d'utiliser au moins 3 combinaisons de pratiques RH pour produire des effets positifs sur les divers indicateurs de performance utilisés. Le chercheur avait conclu aussi que cette interdépendance se remarquait aussi au niveau des indicateurs de performance et que certaines performances pouvaient aussi influencer l'implantation et le développement de certaines pratiques RH dans les entreprises béninoises étudiées.

* L'étude de Kim et Wright ${ }^{82}$, en s'appuyant sur la théorie de l'attribution des RH, avait offert pour les entreprises chinoises un modèle contextualisé d'efficacité des pratiques RH en stipulant que le système de travail à engagement élevé sera plus efficace dans un contexte où les employés sont conditionnés à faire confiance aux employeurs et les institutions de réglementation sont moins restrictives, donnant à la direction plus d'autonomie dans les décisions en matière de RH.

L'étude de $\operatorname{Koster}^{83}$, qui s'était basé sur des données d'enquêtes comparatives internationales de 26 pays européens, avait soutenu que c'est l'intensité et la cohérence des pratiques RH qui renforçaient l'engagement organisationnel et l'effort de travail et delà l'amélioration de la performance organisationnelle.

* L'étude de Munjuri ${ }^{84}$, qui était menée auprès de 176 enseignants et fonctionnaires d'établissements catholiques d'enseignement supérieur au Kenya, avait révélé qu'il existait une relation positive directe très forte entre l'évaluation équitable, la rémunération incitative et la performance des employés et que la conception et la sécurité de l'emploi avaient un impact moindre sur la performance si non une relation inverse.

* L'étude de Naqvi et al. ${ }^{85}$, qui avait porté sur 70 projets informatiques hétérogènes dans 24 entreprises pakistanaises, avait confirmé une corrélation et une dépendance des résultats du projet par rapport à la gestion du rendement des $\mathrm{RH}$ et à la qualité de la surveillance de la performance par le gestionnaire du projet.

* L'étude de $\mathrm{Ndao}^{86}$, qui était effectuée auprès d'une soixantaine d'entreprises sénégalaises, avait montré que l'efficacité des pratiques RH dépendait de leur complémentarité et que l'impact des pratiques RH sur les résultats de l'entreprise était tributaire de l'objectif et finalités managériales que se fixait cette dernière.

L'étude de Newman et al. ${ }^{87}$, qui était effectuée auprès de 437 employés de cinq entreprises

\footnotetext{
${ }^{81}$ Hounkou E. : «Les pratiques de gestion des ressources humaines et les performances des entreprises Béninoises : une analyse par la méthode de corrélation canonique ». Revue Internationale sur le Travail et la Société, Vol. 9, N 1, 2011, pp. 17-40.

${ }^{82}$ Kim S. et Wright P. : «Putting Strategic Human Resource Management in Context: A Contextualized Model of High Commitment Work Systems and Its Implications in China », Management and Organization Review, Vol. 7, N 1, 2011, pp. 153-174.

${ }^{83}$ Koster F. : «Able, willing, and knowing : The effects of HR practices on commitment and effort in 26 European countries », The International Journal of Human Resource Management, Vol. 22, $\mathrm{N}^{\circ}$ 14, 2011, pp. 2835-2851.

${ }^{84}$ Munjuri M-G. : «The Effect of HRMP Practices in Enhancing Employee Performance in Catholic Institutions of Higher Learning in Kenya », International Journal of Business Administration, Vol. 2, $\mathrm{N}^{\circ}$ 4, November 2011, pp. 189-224.

${ }^{85}$ Naqvi I-H. Bokhari S-H-A., Aziz S. et Kashif-ur-Rehman: «The impact of HRPM on project outcome », African Journal of Business Management, Vol. 5, $\mathrm{N}^{\circ}$ 21, 2011, pp. 8491-8499.

${ }^{86}$ Ndao A. : «Effets des pratiques de GRH sur la performance économique et financière des entreprises sénégalaises : par quels mécanisme ? 》, Thèse de doctorat d'Etat en Sciences de Gestion soutenue en 2011 à la FASEG/UCAD, Montpellier 3.

${ }^{87}$ Newman A., Thanacoody R. et Hui W. : «The impact of employee perceptions of training on organizational commitment and turnover intentions : A study of multinationals in the Chinese service sector », The International Journal of Human Resource Management, Vol. $22, \mathrm{~N}^{\circ} 8$, 2011, pp. 1765-1787.
} 
multinationales opérant dans le secteur des services chinois, avait souligné l'importance des programmes de formation continue comme outil pour renforcer l'engagement organisationnel affectif des employés et réduire le roulement du personnel.

\section{Les études menées en 2012}

L'étude de Gaafar Mohamed Abdalkrim ${ }^{88}$, qui avait examiné l'impact des pratiques RH $^{89}$ sur la performance organisationnelle dans le secteur bancaire en Arabie Saoudite, avait confirmé l'existence d'une corrélation significative et positive entre l'ensemble des pratiques choisies et la performance organisationnelle et particulièrement la formation et le développement qui avaient montré la corrélation positive la plus élevée avec le rendement des organisations. A l'inverse, la rotation des emplois avait montré la corrélation la moins positive avec le rendement des organisations.

L'étude de Pascal Paillé et al. ${ }^{90}$, qui était menée auprès de 151 membres de l'équipe de direction et des travailleurs de première ligne en Chine, avait apporté des preuves tangibles de la nécessité de se concentrer davantage sur la sélection, la formation et la récompense des employés afin de créer une culture de protection de l'environnement qui soit bénéfique pour la performance environnementale des entreprises.

\section{Les études menées en 2013}

L'étude de Bakotić ${ }^{91}$, qui était menée auprès de 5806 employés de 40 grandes et moyennes entreprises croates, avait montré l'existence d'un lien clair entre la satisfaction au travail des salariés et la performance organisationnelle dans les deux sens, mais avec une intensité assez faible surtout le lien entre la performance organisationnelle et la satisfaction au travail.

L'étude de Bercu ${ }^{92}$, qui était effectuée auprès d'un échantillon de PME roumaines, avait montré que des effets positifs étaient générés sur la performance organisationnelle via des pratiques RH en adéquation avec les facteurs organisationnels internes et externes comme l'environnement, la taille et structure de l'entreprise, les stratégies commerciales, etc. et ceci malgré que pour les entrepreneurs des PME roumaines avaient montré une préoccupation faible pour l'analyse de la performance en termes de pratiques $\mathrm{RH}$.

L'étude de Dorien et al..$^{93}$, qui avait porté sur un échantillon de travailleurs vieillissants, avait montré que l'âge modérait l'effet de deux ensembles de pratiques RH (Les pratiques RH de développement et les pratiques RH de maintenance) sur le bien-être et la performance des organisations. Les résultats obtenus, avaient attesté aussi que l'association entre les pratiques RH de développement et le bien-être s'affaiblit avec l'âge alors que l'association entre les pratiques RH de maintenance et le bien-être des salariés se renforce avec l'âge.

\footnotetext{
${ }^{88}$ Gaafar M-A. : "The Impact of HRMP on Organizational Performance in Saudi Banking Sector », European Journal of Business and Management, Vol. 4, $\mathrm{N}^{\circ}$ 21, 2012, pp. 188-196.

${ }^{89}$ Les pratiques RH retenues dans cette recherche étaient : la formation le développement, l'évaluation du rendement, l'autonomie, la rémunération, la rotation des postes, la participation à la prise de décision, et le système de sélection.

${ }^{90}$ Paillé P., Chen Y., Boiral O. et Jin J. : «The Impact of HRM on Environmental Performance : An Employee-Level Study», Journal of Business Ethics, Vol. 121, N 3, 2014, pp. 451 - 466.

${ }^{91}$ Bakotić D. : «Relationship between job satisfaction and organisational performance », Economic Research, Ekonomska Istraživanja, Vol. 29, $\mathrm{N}^{\circ} 1,2016$, pp. 118-130.

${ }^{92}$ Bercu A-M. : «The Impact Of HRMP on SMEs Performance In Romania », Anale, Seria Stiinte Economice, Timisoara, Faculty of Economics, Tibiscus University in Timisoara, Vol. 0, May 2013, pp. 44-52.

${ }^{93}$ Kooij T-A-M., Guest D., Clinton M., Knight T., Jansen P-G-W. et Dikkers J-S-E. : « How the impact of HR practices on employee wellbeing and performance changes with age », Human Resource Management Journal, Vol 23, N ${ }^{\circ} 1,2013$, pp. 18-35.
} 
L'étude de Loo-See Beh et Leap-Han Loo ${ }^{94}$, menée auprès de 312 cadres et non-cadres de sept grandes sociétés d'assurance malaisiennes, avait révélé que l'alignement stratégique des pratiques $\mathrm{RH}$, l'évaluation du rendement, la communication interne, la planification de carrière, la formation et le développement, le recrutement et la sélection avaient une corrélation positive forte avec le rendement des entreprises étudiées.

\section{Les études menées en 2014}

L'étude d'Amin et al. ${ }^{95}$, qui était menée auprès de 300 employés d'une université publique malaisienne composée d'académiciens et d'administrateurs, avait montré que la planification de carrière, parmi les pratiques RH étudiées ${ }^{96}$, contribuait le plus à la performance universitaire et que la communication ouverte et la participation accrue des employés à la prise de décision concernant leurs plans de carrière amélioraient de manière notable la performance de l'université.

L'étude de García-Carbonell N. et al. ${ }^{97}$, qui était menée auprès d'un échantillon d'entreprise espagnoles, avait montré que les facteurs de contingence suivants : la composition de l'équipe de direction, les attributs démographiques du capital humain et les antécédents des dynamiques internes des systèmes RH avaient une incidence sur le processus stratégique RH et delà sur la performance des entreprise étudiées.

L'étude de Hoch et Kozlowski ${ }^{98}$, à l'aide d'un échantillon de terrain de 101 équipes virtuelles, avait montré que les soutiens structurels et le leadership d'équipe partagé étaient plus nombreux et que le leadership hiérarchique était moins fortement lié à la performance des équipes lorsque ces dernières étaient de nature plus virtuelle.

* L'étude de Kurtulus Yilmaz Genç ${ }^{99}$, qui avait examiné la relation entre les caractéristiques des employés travaillant au département de fabrication et les performances perçues de 60 PME turcs, n'avait pas montré une relation positive entre les expertises et compétences des employés et la performance organisationnelle.

* L'étude de Mittal S. et al. ${ }^{100}$, qui avait porté sur 203 cadres et non-cadres des banques indiennes, avait démontré que le développement des RH avec ses trois composantes (Le climat général, la culture OCTAPACE ${ }^{101}$ et les mécanismes du développement des RH) étaient significativement lié à l'engagement organisationnel.

L'étude de Rhee J. et al. ${ }^{102}$, menée auprès de 215 entreprises chinoises, avait indiqué une relation positive entre les pratiques RH et le rendement organisationnel et surtout elle avait pu vérifier l'effet médiateur du soutien des PDG qui étaient sensibilisé à l'importance des pratiques RH.

\footnotetext{
${ }^{94}$ Loo-See Beh et Leap-Han Loo: «HRM Best Practices And Firm Performance : A Universalistic Perspective Approch », Serbian Journal of Management, Vol. 8, № 2, November 2013, pp. 155-167.

${ }^{95}$ Muslim A., Wan K. et Wan I. : «The impact of HMRP on performance Evidence from a public University », The TQM Journal, Vol. $26, \mathrm{~N}^{\circ} 2$, 2014, pp. 125-142.

${ }^{96}$ Les pratiques RH retenues dans cette recherche étaient : Le recrutement et la sélection, la formation, l'évaluation du rendement, la planification de carrière, la définition de l'emploi, la participation des employés et la rémunération

${ }^{97}$ García-Carbonell N., Martín-Alcázar F. et Sánchez-Gardey G. : «Understanding the HRM-Performance Link : A Literature Review on the HRM Strategy Formulation Process », International Journal of Business Administration, Vol. 5, № 2, 2014, pp. 71-81.

${ }^{98}$ Hoch J-E. et Kozlowski S-W-J. : «Leading Virtual Teams : Hierarchical Leadership, Structural Supports, and Shared Team Leadership ». Journal of Applied Psychology, Vol. 99, $\mathrm{N}^{\circ}$ 3, 2014, pp. 390-403.

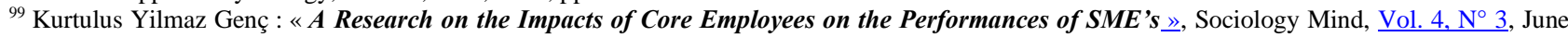
2014, pp. 213-220.

${ }^{100}$ Mittal S., Gupta V. et Motiani M. : «Relation between human resource development climate and organisational commitment : empirical study in Indian banking sector », International Indian Journal of Culture and Business Management, Vol. 12, $\mathrm{N}^{\circ}$ 2, 2016, pp. $204-224$.

${ }^{101}$ OCTAPAC est un acronyme comprenant : Ouverture, Confrontation, Confiance, Autonomie, Proactivité, Authenticité et Collaboration.

${ }^{102}$ Rhee J., Zhao et Kim C. : «Effects of HRMP on Chinese Firms Organizational Performance : The Moderating Effect of CEO Support », Asian Social Science, Vol. 10, $\mathrm{N}^{\circ} 13,2014$, pp. 210-221.
} 
L'étude de Zhang et al. ${ }^{103}$, qui était menée auprès d'un échantillon de 700 employés en Chine, avait montré que les systèmes de travail à haute performance étaient positivement lié à la satisfaction et aux perceptions des employés de la performance sociale des entreprises. D'autre part, les chercheurs avaient stipulé que la satisfaction médiatise pleinement la relation entre les systèmes de travail à haute performance et l'engagement affectif des employés.

\section{Les études menées en 2015}

L'étude de Fabi et al. ${ }^{104}$, qui était effectué auprès de 730 employés dans différentes organisations canadiennes, avait fait apparaître une véritable causalité entre les systèmes de travail à haute performance ${ }^{105}$ et l'intention de quitter l'établissement en mettant en évidence le rôle médiateur joué par la satisfaction au travail et l'engagement organisationnel. De plus, les résultats avaient démontré un effet synergique des systèmes de travail à haute performance, ce qui signifie que les effets combinés des trois ensembles de pratiques RH étudiés étaient supérieurs à la somme de chaque ensemble pris individuellement.

* L'étude de Jeong et Choi ${ }^{106}$, qui était effectuée auprès de 632 entreprises manufacturières en Corée du Sud, avait montré que les systèmes de travail à haute performance avaient un effet direct sur la performance des organisations et que dans le même temps, la présence d'une fonction RH influente intensifiait l'effet des systèmes de travail à haute performance sur les performances.

* L'étude de Mufeed ${ }^{107}$, qui était menée auprès de 80 salarié de la State Bank of India au Jammu-etCachemire, avait pu apprécier la contribution de quelques pratiques RH comme le climat général, la culture, la sélection, la définition des emplois, la planification de carrière, la participation des employés, le système d'évaluation du rendement, la formation et la rémunération, à la performance organisationnelle de la dite banque.

* L'étude de Muduli ${ }^{108}$, qui était effectuée auprès d'une entreprise opérante dans le secteur de l'électricité en Inde, avait montré que le système de travail à haute performance ${ }^{109}$ influençait la performance organisationnelle à travers un environnement de développement favorable basé sur l'ouverture, la confiance, l'authenticité, la proaction, l'autonomie et la collaboration.

L'étude de Mutahi et Busienei ${ }^{110}$, qui était effectuée auprès de quelques universités publiques au Kenya, avait révélé que les pratiques de gestion des récompenses, de formation et de perfectionnement et de ressourcement influaient sur la performance des dites universités publiques.

* L'étude de Sagwa et al., ${ }^{111}$ qui était menée auprès de 60 sociétés cotées à la NSE ${ }^{112}$, avait révélé des résultats surprenants dans la mesure où les résultats des employés n'étaient pas médiateurs dans la

\footnotetext{
${ }^{103}$ Zhang M., Di Fan D. et Zhu C-J. : «High-performance work systems, corporate social performance and employee outcomes : Exploring the missing links », Journal of Business Ethics, Vol. 120, № 3, 2014, pp. 423-435.

${ }^{104}$ Fabi B., Lacoursière R. et Raymond L. "Impact of high-performance work systems on job satisfaction, organizational commitment, and intention to quit in Canadian organizations », International Journal of Manpower, Vol. 36, N 5, 2015, pp. 772-790.

${ }^{105}$ Les auteurs avaient retenu trois ensembles de pratiques $\mathrm{RH}$ : 1'amélioration des compétences, l'amélioration de la motivation et l'amélioration des opportunités comme systèmes de travail à haute performance

${ }^{106}$ Jeong D-Y. et Choi M. : «The impact of high-performance work systems on firm performance : The moderating effects of the human resource function's influence », Journal of Management \& Organization, Vol. 22, $\mathrm{N}^{\circ}$ 3, May 2016, pp. 328-348.

${ }^{107}$ Mufeed S.A. et Gulzar L. : «Impact Of HRMP On Organizational Performance : An Emprical Study Of State Bank Of India », International Journal of Management Research, Vol. 3, N 5, 2015, pp. 286-300.

${ }^{108}$ Muduli A. : "High performance work system, HRD climate and organisational performance: An empirical study », European Journal of Training and Development, Vol. 39, $\mathrm{N}^{\circ} 3,2015$, pp. 239-257.

${ }^{109}$ Le système de travail à haute performance considéré dans cette étude était composé de la rémunération de groupe, les décisions participatives décentralisées, les équipes de travail autogérées, les événements sociaux et familiaux et l'évaluation basée sur les objectifs de l'équipe ainsi que la culture OCTAPAC (Ouverture, Confrontation, Confiance, Autonomie, Proactivité, Authenticité et Collaboration).

${ }^{110}$ Mutahi N. et Busienei J-R. : «Effect Of HMRP On Performance Of Public Universities In Kenya », International Journal of Economics, Commerce and Management, United Kingdom, Vol. 3, N $^{\circ}$ 10, October 2015, pp. 696-736.

${ }^{111}$ Sagwa E-V., Evans V., K'Obonyo P. et Ogutu M. : «HRMP And Performance Firms Listed On The Nairobi Securities Exchange », European Journal of Business and Management, Vol. 7, $\mathrm{N}^{\circ} 14,2015$, pp. 89-96.

${ }^{112}$ Nairobi Securities Exchange
} 
relation entre les pratiques $\mathrm{RH}$ et le rendement des entreprises.

L'étude de Sedok ${ }^{113}$, qui était menée auprès de 103 PME togolaises, avait montré que la cohérence interne entre les pratiques RH à elle seule n'était pas suffisante pour pouvoir influencer la performance des PME togolaises et qu'il fallait également chercher à aligner les pratiques RH sur la stratégie correspondante. De ce fait, le chercheur avait avancé que l'approche configurationnelle constitue une alternative stratégique valable pour les PME togolaises.

L'étude de Yilmaz et Bulut ${ }^{114}$, qui était menée auprès de 314 entreprises du secteur textile membre de la Chambre de Commerce et d'Industrie de Bursa en Turquie, avait montré que les pratiques RH par leur capacité de fournir aux organisations des employés bien orientés et en harmonie avec les valeurs de l'organisation et surtout en assurant des expériences profitables pour les employés, les organisations arrivaient à accroître leur performance organisationnelle.

L'étude de Zehira et al. ${ }^{115}$, qui était effectuée auprès de dirigeants de quatre banques islamiques opérant en Turquie, avait montré que les pratiques de gestion stratégique RH avaient une influence positive sur la performance d'innovation et les capacités globales qui à leurs tours avaient un effet médiateur dans cette relation.

\section{Les études menées en 2016}

L'étude de Khashman et Khashman ${ }^{116}$, qui était menée auprès de 170 employés de 39 hôpitaux de la ville d'Amman en Jordanie, avait pu montrer que, par l'application de Système d'Information, les pratiques RH comme l'analyse de l'emploi, le recrutement, la sélection, l'évaluation du rendement et la communication avaient un impact positif significatif sur la performance organisationnelle.

* L'étude de Koster et Wittek ${ }^{117}$, qui avait porté sur 16701 employés vivant dans 23 pays européens, avait apporté un soutien mitigé à la corrélation entre les pratiques RH (discrétion et amélioration des compétences «originalité / »valeur») d'un côté et le niveau d'ouverture commerciale et les investissements directs étrangers des pays de l'autre côté et que la mondialisation économique était souvent mentionnée comme un facteur important dans la compréhension des relations organisationnelles.

L'étude de Naveed et Mansoor ${ }^{118}$, qui était menée auprès de 361 succursales d'une banque commerciale pakistanaise, avait soutenu le fait que la GRH électronique (GRH-E ou E-HRM ${ }^{119}$ ) améliore la qualité et l'efficacité des pratiques RH par une prestation efficace des services RH, des économies de coûts et surtout par la transformation du rôle de la fonction RH d'expert administratif en partenaire stratégique.

\footnotetext{
${ }^{113}$ Sedok K. : «Les pratiques de GRH et les performances des PME au Togo : Approche configurationnelle Idéal-type », $6^{\mathrm{ième}}$ édition des SERGe Days, Avril 2018, Dakar, Sénégal.

${ }_{114}^{11}$ Ramazan Yilmaz et Fatih Mehmet Bulut : «The Effect Of HRM On Organizational Performance », KNUV, Vol. 2, № 44, 2015 , pp. 5-13.

${ }_{115}$ Zehira C., Üzmez A. et Yıldız H. : «The Effect of SHRM Practices on Innovation Performance : The Mediating Role of Global Capabilities », 12th International Strategic Management Conference (ISMC), 28-30 October 2016, Antalya, Turkey, Procedia - Social and Behavioral Sciences Vol. 235, 2016, pp. 797-806.

${ }^{116}$ Iyad Mohammad Ali Khashman et Aysar Mohammad Khashman : «The Impact of Human Resource Information System (HRIS) Applications on Organizational Performance (Efficiency and Effectiveness) in Jordanian Private Hospitals », Journal of Management Research, Vol. 8, $\mathrm{N}^{\circ} 3$, 2016, pp. 31-44.

${ }^{117}$ Koster F. et Wittek R. : «Competition and constraint: Economic globalization and human resource practices in 23 European countries », Employee Relations, Vol. 38, № 2, 2016, pp. 286-303.

${ }^{118}$ Naveed Iqbal et Mansoor Ahmad : «Unveiling The E-HRM-Performance Link : Evidence From Pakistani Banking Industry », GUJR, Vol. 32, $\mathrm{N}^{\circ} 1$, June 2016, pp. 65-75.

${ }^{119}$ E-HRM est l'intégration de tous les systèmes et activités RH utilisant les technologies Web. Simplement, lorsque les RH utilisent Internet ou des technologies connexes pour soutenir leurs activités, leurs procédures et leurs processus, il devient alors une GRH électronique.
} 
L'étude de Robindro et Kassa ${ }^{120}$, qui était menée auprès de 169 universitaires et personnel de soutien de l'université Debre Brehan en Ethiopie, avait révélé que les pratiques RH : recrutement et sélection, formation et perfectionnement, évaluation du rendement et rémunération ont une relation significative avec le rendement de cette université.

* L'étude de Saira Hassan ${ }^{121}$, qui était menée par auprès de 68 employés de l'industrie textile du Pakistan, avait montré que l'impact des pratiques RH à haute performance comme la sélection, la formation, la planification de carrière, la rémunération, l'évaluation du rendement, la définition des emplois et la participation des employés sur la performance des employés était très grande.

L'étude de Zehira et al. ${ }^{122}$, qui était effectuée auprès des dirigeants de quatre banques islamiques opérantes en Turquie, avait montré que les pratiques de gestion stratégique des RH avaient une influence positive sur la performance d'innovation et que les capacités spécifiques des dirigeants, de manière globale, avaient un effet médiateur dans cette relation.

\section{Les études menées en 2017}

L'étude de Bamel et al. ${ }^{123}$, qui était effectuée auprès de 294 gestionnaires indiens, avait examiné la relation entre l'efficacité des rôles (ER) et l'efficacité du management (EM) dans le contexte indien. Les résultats avaient indiqué que les dimensions de l'ER étaient significativement et positivement liées à l'EM et ces résultats sont particulièrement importants par rapport à la transformation des cultures du travail et des environnements organisationnels indiens. Les auteurs avaient suggéré que les composants liés aux dimensions de l'ER pouvaient être utilisées comme moyen de renforcer l'efficacité des employés.

L'étude de Bouckenooghe et al. ${ }^{124}$, qui était menée auprès de 280 employés de sept organisations pakistanaises, avait exploré les relations de l'affectivité négative avec le rendement au travail et les intentions de roulement. Les résultats avaient montré que si l'affectivité négative nuit au rendement au travail, cet effet était atténué au fur et à mesure que l'affectivité négative augmente. Les chercheurs avaient montré en outre que l'effet principal négatif linéaire de l'affectivité négative sur le rendement au travail est plus prononcé lorsque les employés subissent moins de stress au travail lié au temps.

L'étude effectuée par Bandibeno et Ndongo $^{125}$, qui était effectuée au près d'un échantillon de 166 collectivités territoriales décentralisées (CTD) au Cameroun, avait pu montrer qu'il existait un lien positif et significatif entre les pratiques $\mathrm{RH}$ et la performance sociale des CTD et que la formalisation des pratiques $\mathrm{RH}$ au sein des CTD est sous-jacente à la modernisation de la gestion locale.

L'étude de Chordiya et al. ${ }^{126}$, qui avait utilisé des données provenant de quatre États américains

\footnotetext{
${ }^{120}$ Nongmaithem R. et Biniam K. : «The Impact of HRMP on Organizational Performance : A Study on Debre Brehan University », International Jornal of Recent Advances in Organizational Behaviour and Decision Sciences, Vol. 2, N ${ }^{\circ}$ 1, 2016, pp. 643-662.

${ }^{121}$ Saira H. : «Impact of HRMP on Employees Performance », International Journal of Academic Research in Accounting, Finance and Management Sciences, Vol. 6, $\mathrm{N}^{\circ}$ 1, January 2016, pp. 15-22.

${ }^{122}$ Zehira C., Üzmez A. et Yıldızc H. : «The Effect of SHRM Practices on Innovation Performance : The Mediating Role of Global Capabilities », 12th International Strategic Management Conference (ISMC), 28-30 October 2016, Antalya, Turkey, Procedia - Social and Behavioral Sciences Vol. 235, 2016, pp. 797-806.

${ }^{123}$ Bamel U., Budhwar P., Stokes P. et Paul H. : «Dimensions of role efficacy and managerial effectiveness : evidence from India », Journal of Organizational Effectiveness : People and Performance, Vol. 4, No 5, 2017, pp. 218-237.

${ }^{124}$ Bouckenooghe D., Raja U, Butt A-N., Abbas M. et Bilgrami S. : "Unpacking the curvilinear relationship between negative affectivity, performance, and turnover intentions : The moderating effect of time-related work stress », Journal of Management \& Organization, Vol. 1, 2016, pp. 1-19.

${ }_{125}$ Bandibeno $\mathrm{I}-\mathrm{K}$. et Ndongo J-C-A : «Pratiques de gestion des ressources humaines et performance sociale des collectivités territoriales décentralisées au Cameroun ", Mondes en développement, Vol. 2, № 178, 2017, pp. 139-154.

${ }^{126}$ Chordiya R., Sabharwal M. et Goodman D. : «Afective organizational commitment and job satisfaction : A cross-national comparative study », Public Administration, Vol. 95, $\mathrm{N}^{\circ} 1,2017$.
} 
(Oregon, Floride, Washington et Utah) et d'Inde, avait indiqué que, dans les contextes des deux pays, la satisfaction au travail a un impact positif significatif sur l'engagement organisationnel affectif et que, par rapport aux quatre États américains de l'Oregon, de la Floride, de Washington et de l'Utah, l'engagement organisationnel affectif était nettement plus élevé chez les gestionnaires publics indiens.

* L'étude de Delaney et Huselid ${ }^{127}$, qui était effectuée auprès des employés de 590 entreprises à but lucratif et sans but lucratif, avait montré que les associations entre les pratiques RH telles que la sélectivité en matière de formation et de dotation, et les mesures perceptuelles du rendement des entreprises étaient très positives et que ces systèmes $\mathrm{RH}$ entrainaient des performances organisationnelles plus élevées.

L'étude de Moon et al. ${ }^{128}$ avait examiné si les codes d'éthique des organisations coréennes et britanniques avaient une influence sur les relations de travail et les comportements corrompus des salariés. Les résultats avaient montré que, contrairement aux organisations britanniques, les organisations coréennes approuvaient des codes d'éthique qui mettent davantage l'accent sur les relations hiérarchiques et contenaient des prescriptions pour les personnes occupant des rangs supérieurs ou subalternes. Les codes éthiques semblaient également être davantage axés sur la prévention des abus de pouvoir dans les organisations coréennes par rapport aux organisations britanniques. Enfin, contrairement aux organisations britanniques, les organisations coréennes autorisaient souvent des échanges descendants (et non ascendants), ce qui suggère que dans les échelons supérieurs, la bienveillance peut être plus normative dans les organisations coréennes que dans les organisations britanniques.

- L'étude de Mustafa et al. ${ }^{129}$, qui avait utilisé une enquête transversale, avec des données collectées auprès de 120 étudiants en commerce engagés dans des équipes de projet dans une université norvégienne, avait exploré si les valeurs culturelles individuelles de distance de pouvoir, d'évitement de l'incertitude et de masculinité-féminité interagissent avec les valeurs collectivistes individuelles pour influencer l'orientation du travail d'équipe et ensuite examiner l'influence de l'orientation du travail d'équipe sur l'apprentissage personnel en explorant davantage le rôle de la congruence des valeurs perçues dans cette relation. Les résultats avaient indiqué que le lien entre le collectivisme et l'orientation du travail d'équipe était plus fort pour les membres de l'équipe qui avaient obtenu un score élevé par rapport aux valeurs d'évitement de l'incertitude et que la relation était plus faible pour les membres de l'équipe qui avaient approuvé les valeurs de distance de grande puissance. L'orientation vers le travail d'équipe était significativement associée à l'apprentissage personnel indépendamment du degré de congruence de valeur perçue entre les membres individuels et les autres membres de l'équipe.

* L'étude de Nassar ${ }^{130}$, qui était effectuée auprès de 257 employés dans neuf hôtels quatre et cinq étoiles au Caire et à Alexandrie, avait montré que seule la communication affectait l'engagement de maintien, alors que l'embauche, la formation et le perfectionnement, les évaluations du rendement, la rémunération et la communication étaient tous liés positivement et significativement à l'engagement

\footnotetext{
${ }^{127}$ Delaney J-T. et Huselid M-A. : «The Impact of Human Resource Management Practices on Perceptions of Organizational Performance », Academy of Management Journal, Vol. 39, № 4, November 2017. 1996

${ }^{128}$ Moon C., Uskul A-K. et Weick M. : «On Culture, Ethics and Hierarchy: How Cultural Variations in Hierarchical Relations Are Manifested in the Code of Ethics of British and Korean Organizations », Journal of Applied Social Psychology, Vol. 48, № 1, 2017, pp. 15-27.

${ }^{129}$ Mustafa G., Glavee-Geo R., et Rice P-M. : «Teamwork orientation and personal learning: The role of individual cultural values and value congruence », Journal of Industrial Psychology, Vol. 43, 2017, pp. 14-46.

${ }^{130}$ Nassar M-A. : «Human resource management practices and organizational commitment in four and five star hotels in Egypt », Journal of Human Resources in Hospitality et Tourism, Vol. 17, $\mathrm{N}^{\circ}$ 1, 2018, pp. 1-21.
} 
affectif et delà découlait un rendement au travail meilleur.

* L'étude de Raja et al. ${ }^{131}$, en utilisant des données de terrain décalées sur 3 vagues $(\mathrm{N}=151)$ provenant d'employés à temps plein, avaient examiné comment l'intimidation en milieu de travail se manifeste comme un conflit entre le travail et la famille par l'épuisement professionnel. Les résultats avaient montré que l'intimidation en milieu de travail conduisait à l'épuisement professionnel, qui à son tour épuisait les ressources énergétiques des individus et provoquait un plus grand conflit travailfamille.

L'étude de Ramaprasad et al. ${ }^{132}$, qui était une revue de 63 articles empiriques publiée entre 2001 et 2016 et qui avaient étudié la relation entre les pratiques RH et l'engagement organisationnel, avait soutenu une relation indirecte entre les pratiques ou systèmes RH et l'engagement organisationnel médiée par un environnement organisationnel caractérisé par des facteurs tels que : la satisfaction au travail, l'adéquation personne-organisation et un climat organisationnel favorable.

L'étude de Saridakis et al., ${ }^{133}$, qui était une agrégation de huit études longitudinales sur la performance des pratiques $\mathrm{RH}$, avait montré que les pratiques RH à hautes performances intégrées s'intégraient et se renforçaient mutuellement entrainant un impact plus fort sur la performance aussi bien opérationnelle que financière des entreprises.

\section{Les études menées en 2018}

* L'étude de Chukwuka et Nwakoby ${ }^{134}$, qui était effectuée auprès de 250 salariés de l'industrie de l'assurance nigériane, avait confirmé que malgré qu' 'il y avait un effet faible et insignifiant des pratiques RH sur la rétention des employés dans l'industrie de l'assurance nigériane, les pratiques RH avaient un effet positif et significatif sur la performance des employés.

* L'étude de Feitosa et al. ${ }^{135}$, grâce à un processus de comparaison et de mise en contraste, voulait démontrer comment la recherche axée sur l'impact de la culture sur le fonctionnement des équipes fait progresser la compréhension théorique courante de l'efficacité de ces dernières. La plupart des analyses effectuées par les auteurs avaient révélé qu'il existait des conditions limites importantes entourant les hypothèses communes d'efficacité des équipes lorsque la culture est prise en compte.

* L'étude de Gadelrab et al. ${ }^{136}$, qui était effectuée auprès de 2914 employés travaillant dans le secteur public de neuf pays arabes, avait évalué la justice organisationnelle dans les perspectives culturelles arabes. Les résultats avaient montré que les inter-corrélations de la dimension de la justice organisationnelle se sont avérées modérées à élevées et indépendantes des groupes culturels et ceci malgré la variété des cultures des neuf pays arabes étudiés.

* L'étude de Khal Hamza ${ }^{137}$ avait examiné la relation entre la culture nationale et la culture organisationnelle dans le contexte des organisations des secteurs privé et public au Kurdistan irakien. Les résultats de cette étude avaient montré que la culture nationale a un impact sur la

\footnotetext{
${ }^{131}$ Raja U., Javed Y. et Abbas M. : «A Time Lagged Study of Burnout as a Mediatorin the Relationship Between Workplace Bullying and WorkFamily Conflict », International Journal of Stress Management, Vol. 25, ํ 4, 2018, pp. 377-390.

${ }^{132}$ Ramaprasad B-S., Prabhu K-N., Lakshminarayanan S. et Pai Y-P. : «Human resource management practices and organizational commitment : a comprehensive review (2001-2016) », Prabandhan : Indian Journal of Management, Vol. 10, 우 10, 2017, pp. 7-23.

${ }^{133}$ Saridakis G., Lai Y. et Cooper C-L. : «Exploring the relationship between HRM and firm performance : A meta-analysis of longitudinal studies », Human Research Management Review, Vol. 27, 2017, pp. 87-96.

${ }^{134}$ Chukwuka E-J. et Nwakoby N-P. : «Effect of Human Resource Management Practiceson Employee Retention and Performance in Nigerian Insurance Industry », World Journal of Research and Review, Vol. 6, Nㅜ 4, April 2018, pp. 27-41.

${ }^{135}$ Feitosa J., Grossman R. et Salazar M. : «Debunking key assumptions about teams : The role of culture », American Psychologist, Vol. 73, $\mathrm{N}^{\circ} 4$, 2018, pp. 376-389.

${ }^{136}$ Gadelrab H-F., Alkhadher O., Aldhafri S., Almoshawah S., Khatatba Y., Zine El Abiddine F., Alyetama M., Elmsalak S., Tarboush N. et Slimene S. : «Organizational Justice in Arab Countries: Investigation of the Measurement and Structural Invariance », Cross-Cultural Research, Vol. 54, $\mathrm{N}^{\circ} 1,2020$, pp. 3-27.

${ }^{137}$ Khal Hamza S-H. : «The Influence of National Culture on Organizational Culture in Private and Public Sector Organizations in Iraqi Kurdistan, A Cross - Sectorial Comparison », Journal of Human Sciences, Vol. 22, № 4, 2018, pp. 323-346.
} 
culture organisationnelle dans le secteur privé où dominait la culture de la hiérarchie suivie de la culture du marché alors qu'aucun effet n'avait été observée dans les organisations du secteur public où dominait la culture hiérarchique suivie par la culture clanique.

* L'étude de Kweku Otoo ${ }^{138}$, qui était menée auprès de 600 employés de l'industrie hôtelière ghanéenne, avait révélé que les compétences des employés sont des médiateurs directs dans la relation pratiques $\mathrm{RH}$ et performance organisationnelle.

* L'étude de Mucelli et al. ${ }^{139}$, qui s'inscrit parmi les études qui considèrent la culture nationale comme un facteur comportemental capables d'influencer les processus de gestion et de prise de décision et en particulier les pratiques de comptabilité de gestion, avait montré que la culture nationale a un rôle bien reconnu, principalement modérateur, dans les pratiques de gestion surtout dans l'élaboration des processus de prise de décision participative grâce au calcul des coûts basés sur les activités en fonction du temps (Time-Driven Activity Based Costing (TDABC)).

* L'étude de Saridakis et al. ${ }^{140}$, en utilisant un grand ensemble de données appariées employeuremployé de Grande-Bretagne (WERS2011), avait montré que l'augmentation de la satisfaction au travail était susceptible d'entrainer un engagement organisationnel amélioré, mais cette étude avais aussi montré également qu'un plus grand engagement organisationnel conduisait à des niveaux plus élevés de la satisfaction au travail suggérant de ce fait que la satisfaction au travail et l'engagement organisationnel étaient susceptibles d'être liés réciproquement.

* L'étude de Torlak et al. ${ }^{141}$, effectuait auprès de 440 employés travaillant dans l'industrie hôtelière Irano-Türk, avait démontré que les pratiques $\mathrm{RH}^{142}$ favorisaient l'engagement organisationnel, la performance individuelle au travail et la performance organisationnelle ce qui était essentiel à une qualité de service élevée dans l'industrie hôtelière Irano-Türk.

\section{Les études menées en 2019}

* L'étude d'Alatailat et al. ${ }^{143}$, à l'aide de données transversales obtenues auprès de banques commerciales en Jordanie, avait montré que le contenu des pratiques RH à haut rendement telles qu'elles étaient identifiées dans les pays développés, stimulait d'un pays en développement en dehors du monde occidental.

* L'étude de Binti Mohd Taib et al. ${ }^{144}$, qui était effectuée auprès de 318 employés du secteur public de la promotion immobilière, voulait, avait révélé que les pratiques $\mathrm{RH}$, notamment la formation et le perfectionnement, la rémunération, la sécurité d'emploi et la promotion, étaient importantes et positivement liées au rendement des employés. Les résultats avaient montré également que l'engagement des employés peut servir de médiateur dans la relation entre les dites pratiques RH et la performance des employés.

\footnotetext{
${ }^{138}$ Kweku Otoo F-N. : «Human resource management (HRM) practices and organizational performance : The mediating role of employee competencies », International Journal of Management Studies, Vol. 5, ํㅜ 3, July 2018, pp. 91-105.

${ }^{139}$ Mucelli A., Spigarelli F. et Lepore D. : «National Culture for a Participatory Time-driven Activity Based Costing : A Conceptual Framework and Research Agenda ». International Journal of Business Administration, Vol. 9, $\mathrm{N}^{\circ}$ 2, 2018, pp. 56-66.

${ }^{140}$ Saridakis G., Lai Y., Muñoz Torres R-I. et Gourlay S. : «Exploring the relationship between job satisfaction and organizational commitment : an instrumental variable approach », The International Journal of Human Resource Management, January 2018.

${ }^{141}$ Torlak N-G., Kuzey C. et Ragom M. : «Human resource management, commitment and performance links in Iran and Turkey», International Journal of Productivity and Performance Management, Vol. 67, $\mathrm{N}^{\circ}$ 2, June 2018.

${ }^{142}$ Les pratiques $\mathrm{RH}$, retenues dans cette étude étaient : la récompense, le travail d'équipe, la description de poste, la délégation et la gestion de carrière

${ }^{143}$ Alatailat M., Elrehail H. et Okechukwu Lawrence Emeagwali : «High performance work practices, organizational performance and strategic thinking : A moderation perspective », International Journal of Organizational Analysis, 2019.

${ }^{144}$ L'étude de Binti Mohd Taib N., Hj M., Saludin H-N. : «The effects of Human Resources Management Practices on employee performance with the mediating role of employee engagement : Preparing for industrial revolution 4.0 », 2019.
} 
* L'étude de Chakraborty et Biswas W. ${ }^{145}$, qui avait utilisé des données primaires collectées auprès de différentes industries manufacturières d'Inde, avait montré que les programmes de planification RH (Dotation et Relève) et les stratégies de gestion des talents donnaient un meilleur résultat en atteignant l'objectif stratégique de l'entreprise et de ce fait augmentaient la performance de l'organisation.

* L'étude d'Elrehail et al. ${ }^{146}$, qui était effectuée auprès de 439 employés chypriotes des hôtels cinq étoiles, avait révélé que les pratiques RH avaient un effet significatif sur l'avantage concurrentiel, mais la satisfaction des employés n'avait aucun effet dans cette relation et delà sur l'obtention d'un avantage concurrentiel pour les hôtels cinq étoiles du nord de Chypre.

* L'étude de Gleibs et Alvarado ${ }^{147}$ avait analysé, pour 631 professionnels travaillant au Chili et 520 professionnels du Royaume-Uni, l'impact du statut de travail (CDI ou CDD) sur les résultats du point de vue de l'identité sociale. Les chercheurs avaient constaté que le statut de travail influençait la relation entre l'identification de l'organisation et de l'équipe avec le bien-être affectif au travail, mais pas avec le comportement de citoyenneté organisationnelle ou les intentions de de quitter l'établissement. Ces résultats permettaient aux chercheur de comprendre la dynamique de l'identification sociale sur le lieu de travail qui était liée au statut de travail dans le contexte de deux pays différents : Le Chili, un pays caractérisé par des taux élevés de contrats de travail à durée déterminée et occasionnels et le Royaume-Uni avec des conditions de travail comparativement moins atypiques.

* L'étude de Mehwich et al. ${ }^{148}$, qui était effectuée auprès de 218 employés pakistanais du secteur des télécommunications, avait montré qu'à l'exception de la pratique « récompense et reconnaissance » la relation entre l'ensemble des pratiques RH étudiées ${ }^{149}$ et l'engagement organisationnel était médié par la satisfaction au travail.

* L'étude de Naveed et al. ${ }^{150}$, qui était effectuée auprès de 700 cadres supérieurs de banques pakistanaises, avait montré que la gestion électronique des RH (e-HRM) amélioraient la confiance organisationnelle et les résultats de productivité et que la confiance impersonnelle assurait une médiation partielle dans cette relation (e-HRM) / productivité des employés.

* L'étude de Pilar González-Navarro et al. ${ }^{151}$, qui a été menée auprès d'échantillon de 277 travailleurs (127 travailleurs chinois correspondant à une culture collectiviste verticale et 150 travailleurs espagnols représentant une culture individualiste horizontale), avait comme but d'examiner si la qualité de la relation avec le leader prédit l'engagement et la satisfaction, et si la résilience modère cette relation dans deux contextes culturels différents (espagnol et chinois). Les résultats avaient révélé pour les deux échantillons que la qualité de la relation avec le leader prédit positivement l'engagement et la satisfaction mais le rôle modérateur de la résilience varie selon les cultures : La résilience avait modéré cette relation de la qualité de la relation avec le leader aussi bien avec

\footnotetext{
${ }^{145}$ Chakraborty D. et Biswas W. : «Evaluating the impact of human resource planning programs in addressing the strategic goal of the firm $:$ An organizational perspective », Journal of Advances in Management Research, Vol. 16, N 5, November 2019, pp. 659-682.

${ }^{146}$ Elrehail H., Harazneh I., Abuhjeeleh M., Alzghoul A., Alnajdawi S. et Hussein Ibrahim H-M. : «Employee satisfaction, human resource management practices and competitive advantage: The case of Northern Cyprus », European Journal of Management and Business Economics, Vol. 29, $\mathrm{N}^{\circ} 2$ 2, 2020, pp. 125-149.

${ }^{147}$ Gleibs I-H. et Alvarado L-A. : «The impact of non-standard work arrangements and communication climate on organisational and team identification and work-related outcomes amongst millennial in Chile and the UK». Social Psychological Bulletin, Vol. 14, $\mathrm{N}^{\circ} 3,2019$, pp. 1-32.

${ }^{148}$ Mehwish J., Abeera A., Aideed B. et Tania H. : «Human resource practices and organizational commitment : The mediating role of job satisfaction in emerging economy », Cogent Business \& Management, Vol. 6, ํㅜ 1, May 2019. https://doi.org/10.1080/23311975.2019.1608668

${ }^{149}$ Les pratiques RH qui étaient retenues dans cette étude sont : Recrutement et sélection, Formation, Evaluation du rendement, Récompenses et reconnaissance et finalement l'Environnement du travail.

${ }^{150}$ Naveed I., Mansoor A. et Allen M-C. : «Unveiling the relationship between e-HRM, impersonal trust and employee productivity », Manageùent Research Review, Vol. 42, N 7, May 2019, pp. 879-899.

${ }^{151}$ Pilar G-N., Talavera-Escribano E., Rosario Zurriaga-Lloréns et Lucía . Llinares-Insa : «Culture, Work, and Subjective Well-Being: The Role of LMX and Resilience in Spanish and Chinese Cultures », International Journal of Environmental Research and Public Health, Vol. 16, № 24, 2019, pp. $1-16$.
} 
l'engagement qu'avec la satisfaction dans l'échantillon espagnol, alors que dans l'échantillon chinois, la résilience n'avait modéré que la relation entre la qualité de la relation avec le leader et la satisfaction.

* L' étude de Valverde-Moreno et al. ${ }^{152}$, qui était basée sur la $6^{\text {ième }}$ enquête européenne sur les conditions de travail réalisée par Eurofound en 2016, avait comme objectif d'analyser l'influence perçu par les employés du soutien du superviseur (PSS) à un niveau micro et le rôle des valeurs culturelles de «distance de pouvoir » et de «masculinité » au niveau macro sur la participation directe des employés à la prise de décision (PDM). Les résultats avaient indiqué que le PSS avait un impact plus important sur la PDM lorsque les managers de sexe masculin s'adressaient aux femmes. Concernant l'effet modérateur du PSS sur les valeurs culturelles, il était démontré que la masculinité et la distance de pouvoir perdent de leur importance lorsque les employés avaient le soutien de leurs supérieurs.

\section{Les études menées en 2020}

* L'étude d'Arnulf et Larse ${ }^{153}$, en administrant un questionnaire sur le leadership multifactoriel auprès de 11 échantillons ethniques différents en anglais, norvégien, allemand, ourdou et chinois, avait montré que les différences observées ne sont pas culturellement dépendantes mais causées par des traductions et une compréhension différentes et que la variance maximale attribuable à la culture n'était qu'un chevauchement unique de 5\% de variation dans les deux échantillons chinois à titre d'exemple.

* L'étude de Junaid et al. ${ }^{154}$, en utilisant des données du Global Entrepreneurship Monitor pour 56 pays pour les années 2008-2013 et utilisant une analyse comparative qualitative, avait montré que les antécédents institutionnels culturels et cognitifs, combinés aux antécédents sociaux-normatifs, créaient des configurations différentes qui conduisaient à des niveaux plus élevés d'activité entrepreneuriale des hommes et des femmes dans des économies axées sur les facteurs de travail et la recherche d'efficacité.

* L'étude de Nguyen et Belaounia ${ }^{155}$, effectuait auprès d'un échantillon d'acquéreurs français, avait montré que ce n'est pas la distance géographique ni la différence linguistique mais c'est plutôt la distance culturelle qui accroit la probabilité d'un paiement en espèces. Les chercheurs avaient montré également que la dimension culturelle la plus importante était l'aversion a l'incertitude et que la distance culturelle joue un rôle plus grand lorsque l'intégration de la société cible dans la structure organisationnelle de l'acquéreur apparait plus délicate.

Dans l'ensemble, les 116 études répertoriées, toute approches confondues, avaient validé empiriquement l'impact des pratiques RH sur la performance des organisations. En plus de ce constat, on ne peut passer sous silence les approches adoptées par Doty et Delery ${ }^{156}$, qui ont attiré notre attention, du fait que leurs auteurs s'étaient basés sur les trois principales approches utilisées dans les recherches empiriques (universalistes,

\footnotetext{
${ }^{152}$ Valverde-Moreno M., Torres-Jiménez M., Lucia-Casademunt A-M. et Muñoz-Ocaña Y. : «Cross Cultural Analysis of Direct Employee Participation : Dealing With Genderand Cultural Values », Frontiers in Psychology, Vol. 10, ํ 723, 2019, pp. 1-13.

${ }^{153}$ Arnulf J-K. et Larsen K-R. : «Culture Blind Leadership Research : How Semantically Determined Survey Data May Fail to Detect Cultural Differences », Frontiers in Psychology, Vol. 11, N 176, 2020, pp. 1-18.

${ }^{154}$ Junaid D., Yadav A., Afzal F., Shah I-A., Shanmugam B., Jonkman M., Azam S. et De Boer F. : «The Configurations of Informal Institutions to Promote Men's and Women's Entrepreneurial Activities », Frontiers in Psychology, Vol. 11, Article 1909, 2020, pp. 1-16.

${ }^{155}$ Nguyen P. et Belaounia S. : «Cultural Distance and Payment Method in French Cross-Border Acquisitions », International Management, Vol. $24, \mathrm{~N}^{\circ} 1,2020$, pp. 109-126.

${ }^{156}$ Delery J-E. et Doty D-H. : «Modes of Theorizing in Strategic Human Resource Management : Test of Universalistic, Contingency, and Configurational Performance Predictions », Academy of Management Journal, Vol. 39, 1996, pp. 802-835.
} 
de contingence et configurationnelles). Les auteurs avaient aboutis au constat, qu'en dépit de l'importance de chacune des trois approches prés citées, il est plus pertinent d'adopter l'approche de la contingence ${ }^{157}$.

\section{Illustration De la Variable Culturelle Comme Element Contingent Et Mediateur Dans LA Relation Pratiques RH Et PeRformance des ORganisations}

Les spécialistes en management interculturel attestent que la culture, par sa présence en arrière-plan, a un impact capital et réel sur le management et la gouvernance des organisations et particulièrement sur la performance sociale des organisations ${ }^{158}$. Dans ce sens, pas mal de chercheurs s'accordaient sur la nécessité de mener des études empiriques pour savoir est-ce que oui ou non la variable culturelle peut-elle être considérée comme élément contingent et médiateur dans la relation pratiques $\mathrm{RH}$ et performance des organisations?

Globalement ce rôle est reconnu principalement aux trois études suivantes : L'étude de Newman et Nollen, l'étude de Schuler et Rodovsky et l'étude d'Arcand et al. Nous allons, dans ce qui suit, reprendre dans un ordre chronologique les principaux résultats de ces recherches autres que celles traitant le cas du Maroc, qui seront abordées un peu plus loin dans le cadre du contexte de l'étude.

\section{Les études menées pendant la dernière décennie du $20^{\text {ième }}$ siècle}

* L'étude de Newman et Nollen ${ }^{159}$ : A notre connaissance, cette étude effectuée en 1996 constitue la première étude ayant utilisé la variable culturelle comme élément contingent dans la relation entre les pratiques RH et la performance organisationnelle. Cette étude, qui s'est basée sur des données recueillies dans 176 unités de travail réparties dans dix-huit pays d'Europe et d'Asie et appartenant à une seule compagnie multinationale américaine œuvrant dans le secteur de la haute technologie, a pu démontrer que la performance financière des unités de travail est plus élevée lorsque les pratiques RH sont alignées en fonction de la classification des cultures adoptées. En effet, à titre d'exemple, pour la dimension culturelle «Distance Hiérarchique », les auteurs attestent qu'en cas de distance hiérarchique basse, les unités de travail ayant un caractère participatif sont plus performantes que les unités non participatives et qu'à l'inverse, les établissements caractérisés par une distance hiérarchique élevée, les unités de travail sans caractère participatif sont plus performantes que les unités participatives. En ce qui concerne la dimension culturelle "Contrôle de l'Incertitude », cette étude a mis en exergue le fait que dans les établissements caractérisés par un contrôle d'incertitude élevé, les unités de travail possédant des règles et des directives clairement définies sont plus performantes que celles qui n'en possèdent pas et que par contre, dans les établissements caractérisées par un contrôle d'incertitude bas, les unités de travail ayant moins de règles et de directives définies sont plus performantes que les unités pourvues de règles et de directive clairement définies.

De manière générale, les auteurs ont affirmé quatre de leurs cinq hypothèses et pour eux la variable culturelle agi comme élément contingent dans la relation entre les pratiques RH et la performance organisationnelle. Du fait que la dimension du contrôle de l'incertitude était difficilement mesurable dans leur enquête, la dernière hypothèse portant sur cette dernière dimension n'a pas pu être validée.

* L'étude de Schuler et Rogovsky ${ }^{160}$ : Cette étude, menée en 1998, avait examiné quantitativement l'effet médiateur des différentes dimensions culturelles dans la relation entre les

\footnotetext{
${ }^{157}$ D'autres auteurs comme Lawrence P-R. et Lorsch J-W., dans leur ouvrage : «Adapter les structures de l'entreprise, Intégration ou différenciation ", Les éditions d'organisation, (1989), utilisent un autre concept : L'adaptation de l'organisation à son environnement.

${ }^{158}$ Rhodes J., Walsh P. et Lok P. : «Convergence and divergence issues in strategic management - Indonesia's experience with the Balanced Scorecard in Human Resources Management », The international of Human Resource Management, Vol. 19, N 6, 2008 , pp. 1170 - 1185.

${ }^{159}$ Newman K-L. et Nollen S-D. : «Culture and Congruence : The Fit Between Management Practices and National Culture », Journal of International Business Studies, Vol. 27, 1996, pp. 753-779.

${ }^{160}$ Schuler R-S. et Rogovsky N.: «Understanding compensation practice variations across firms : the impact of national culture », Journal of International Business Studies, Vol. 29, N 1, 1998, pp. 159-177.
} 
pratiques de compensations financières quels soient sous forme de revenus directs ou indirects susceptibles d'être gagnés par les travailleurs et la performance organisationnelle. Les auteurs ont pu démontrer clairement que les pays caractérisés par un contrôle d'incertitude élevé, par des pratiques de compensations basées sur l'ancienneté et les compétences ont un impact certain auprès des employés. Ils soulèvent également que dans les pays caractérisés par un degré d'individualisme élevé, par des pratiques touchant la rémunération basée sur la performance individuelle engendrent une plus grande productivité. Finalement et selon toujours Schuler et Rodovsky, dans les pays caractérisés par un niveau d'individualisme élevé et dans les pays caractérisés par une distance hiérarchique et où le contrôle d'incertitude sont plus bas les régimes d'option d'actions semblent plus adaptés pour entrainer le niveau de performance organisationnel visé.

\section{Les études menées pendant la première décennie du $21^{\text {ième }}$ siècle}

L'étude d'Arcand et al. ${ }^{161}$ : En 2004, Arcand, Fabi et Bayad, en adoptant le paradigme du positivisme aménagé ${ }^{162}$, ont pu développer un modèle de recherche susceptible de mesurer les effets des pratiques $\mathrm{RH}^{163}$ sur la performance ${ }^{164}$ de la firme en prenant en compte l'effet contingent de la culture nationale ${ }^{165}$ et ceci au niveau de plusieurs institutions bancaires américaines (63), françaises (28) et japonaises (16) selon l'hypothèse suivante : "L'utilisation de pratiques RH cohérentes avec la culture nationale, devrait entrainer une meilleure performance organisationnelle».

Schématiquement, leur modèle se résume comme suit :

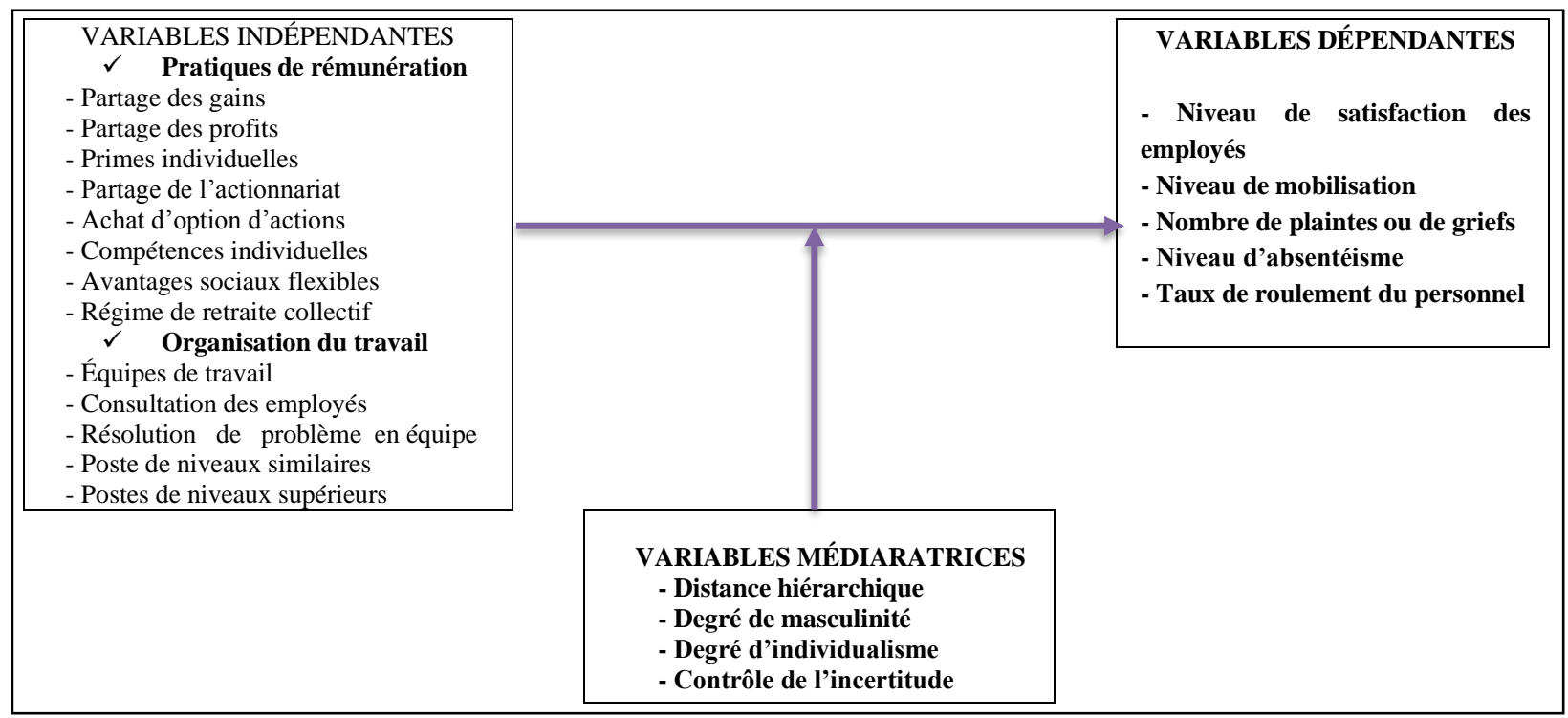

Figure 1 : Modèle d'Arcand (2006)

\footnotetext{
${ }^{161}$ Arcand M., Arcand G., Bayad M. et Fabi B. : «Systèmes De Gestion Des Ressources Humaines Et Performance Organisationnelle », Annals of Public and Cooperative Economics, Vol. 75, N 3, 2004, pp. 497-524.

${ }^{162}$ Ce paradigme permet de découvrir la structure de la réalité tout en se basant sur une cohérence avec les faits.

${ }^{163}$ Les pratiques RH qui représentent les variables indépendantes sont constituées de pratiques en lien avec la rémunération incitative et des pratiques en lien avec la dimension organisation du travail.

${ }^{164}$ La performance qui constitue la variable dépendante n'était autre que la performance sociale que les auteurs avaient construit à l'aide de cinq indicateurs : le niveau de satisfaction au travail des employés, le niveau de mobilisation, le nombre de plainte ou de griefs, le niveau d'absentéisme et le taux de roulement du personnel.

${ }^{165}$ La culture nationale qui constituait la variable modératrice était pour sa part composée des quatre premières dimensions de Hofstede déjà évoquées plus haut : la distance hiérarchique, le degré de masculinité, le degré d'individualisme et le contrôle d'incertitude.
} 
Au final, à l'exception du Japon où les résultats démontrent une relation négative entre les pratiques de partage des profits et la performance signalée, résultat que quelques auteurs relativisent en raison des attentes formulés pour ce pays ${ }^{166}$, cette étude a pu démontrer que lorsque les pratiques RH sont cohérentes avec la culture nationale créent un impact positif sur la performance organisationnelle des entreprises étudiées.

Les travaux d'Arcand, Fabi et Bayad occupent une place non négligeable parmi les recherches se rapportant à cette problématique du lien prétendu entre pratiques RH et Performance organisationnelle, notamment du fait que les auteurs ont cherché à dépasser la seule dimension financière de la performance pour intégrer une dimension très cruciale à savoir la dimension sociale. Néanmoins l'utilisation d'un seul secteur économique (celui des institutions bancaires) même si elle procure une précision dans l'échantillonnage et par le fait même, dans l'interprétation des résultats, nous ne permet pas de généraliser les résultats aux différents secteurs d'activités économiques. C'est pour cette raison, que nous avons eu la conviction que la poursuite dans cette voie ne peut que contribuer à la compréhension de cette problématique surtout à un niveau sectoriel et dans un pays en voie de développement comme le Maroc.

L'étude de Hartog et Verburg ${ }^{167}$, qui était effectuée auprès de 175 organisations de différents secteurs aux Pays-Bas, avait fourni des preuves supplémentaires sur le lien entre les systèmes de travail à haute performance et la performance de l'entreprise et les relie à la culture organisationnelle. Les résultats des différentes analyses effectuées avaient démontré l'existence d'un impact significatif du système de travail à haute performance sur plusieurs composantes de la performance ainsi que des relations positives avec trois orientations de la culture organisationnelle.

L'étude de Manon ${ }^{168}$, qui était effectuée auprès de 450 salariés d'une entreprise opérante au Québec et en Grande Bretagne, avait montré que lorsque les pratiques RH étaient en harmonie avec les dimensions culturelles, la performance sociale des employés est plus grande et de là de fortes chances d'obtenir une performance organisationnelle plus élevée.

L'étude de Wu et Chaturvedi ${ }^{169}$, qui était effectuée auprès de 1383 employés de 23 entreprises de trois pays, avait montré le rôle médiateur de la justice procédurale dans la relation entre les systèmes de travail à haute performance et les attitudes des employés et le rôle modérateur de la distance de pouvoir dans cette relation. Les résultats avaient indiqué que les systèmes de travail à haute performance étaient étroitement lié aux attitudes des employés et que la justice procédurale médiait l'influence des systèmes de travail à haute performance sur les attitudes des employés.

\footnotetext{
${ }^{166}$ Arcand M., Arcand G., et Bayad M. : «Gestion stratégique des ressources humaines et performance de la firme : une validation de l'approche de la contingence », Revue internationale des relations de travail, Vol. 2, $\mathrm{N}^{\circ}$. 2, 2004, pp. 74-93.

${ }^{167}$ Hartog D-N-D. et Verburg R-M. : «High performance work systems, organisational culture and firm effectiveness », Human Resource Management Journal, Vol. 14, $\mathrm{N}^{\circ} 1$, 2004, pp. 55-78.

${ }^{168}$ Bernard M. : "L'effet des pratiques de ressources humaines sur la performance sociale des employés dans un contexte de culture nationale ", Thèse de Doctorat ès Sciences de Gestion soutenue en 2009, Ecole de Management de Strasbourg en cotutelle avec l'Université d'Ottawa.

${ }^{169} \mathrm{Wu}$ P-C. et Chaturvedi S. : «The role of procedural justice and power distance in the relationship between high performance work systems and employee attitudes : A multilevel perspective $»$, Journal of Management, Vol. 35, $\mathrm{N}^{\circ}$ 5, 2009, pp. 1228-1247.
} 
L'étude de Caligiuri et al. ${ }^{170}$, qui était menée auprès d'un échantillon de 3978 étudiants diplômés en Génie de neuf pays, avait exploré les différences interculturelles et individuelles dans la prédiction de la réputation de l'employeur en tant que moteur de l'attraction organisationnelle. Les résultats de cette étude avaient affirmé que qu'au niveau culturel, le collectivisme et, au niveau individuel, le besoin de pouvoir et d'accomplissement étaient liés à l'importance attachée à la réputation de l'employeur. Dans la pratique, les chercheurs estiment que les entreprises devraient envisager d'élaborer leur message de recrutement pour l'adapter aux normes culturelles du pays dans lequel elles recrutent et également encourager les membres de leur personnel de recrutement à adapter leurs messages aux candidats qu'elles tentent d'attirer.

L'étude de Hajro et Pudelko ${ }^{171}$, qui s'était basé sur 70 entretiens centrés sur les problèmes avec des dirigeants des équipes multinationales et des membres de cinq sociétés multinationales, avait révélé que les compétences que les interviewés avaient le plus souvent mentionnées pour un leadership efficace étaient la gestion et le transfert des connaissances. Les résultats avaient en outre indiqué qu'un leader doit être compétent sur le plan interculturel et multilingue afin de motiver les membres des équipes multinationales.

L'étude de Pellegrini et al. ${ }^{172}$, qui était menée auprès de 422 employés (215 au États-Unis : 215 et 207 en Inde : 207), avait montré que le paternalisme a un effet positif significatif sur la satisfaction au travail en Inde, mais la relation n'est pas significative aux États-Unis. Dans les deux contextes culturels, le leadership paternaliste était positivement lié à l'échange leader-membre et à l'engagement organisationnel.

L'étude de Lee et al. ${ }^{173}$ avait examiné à la lumière des variations culturelles nationales les dynamiques sociales qui déterminaient comment les nouveaux arrivants atteignent des niveaux plus élevés d'adéquation avec leur travail et leur organisation. En reconnaissant que les processus sociaux sont liés à la culture, les auteurs avaient soutenu également les effets modérateurs de l'individualisme/collectivisme et de la distance de pouvoir sur le processus de développement de l'adaptation à l'EP.

L'étude de Taras et al. ${ }^{174}$, en utilisant les données de 598 études représentant plus de 200000 personnes, avait méta-analysé la relation entre les 4 premières dimensions originales de valeur

\footnotetext{
${ }^{170}$ Caligiuri P-M., Colakoglu S., Cerdin J-L. et Kim M-S. : «Examining cross-cultural and individual differences in predicting employer reputation as a driver of employer attraction », International Journal of Cross Cultural Management, Vol. 10, $\mathrm{N}^{\circ} 2,2010$, pp. $137-151$.

${ }^{171}$ Hajro A. et Pudelko M. : «An analysis of core-competences of successful multinational team leaders », International Journal of Cross Cultural Management, Vol. 10, $\mathrm{N}^{\circ} 2,2010$, pp. 175-194.

${ }^{172}$ Pellegrini E-K., Scandura T-A. et Jayaraman V. : «Cross-Cultural Generalizability of Paternalistic Leadership : An Expansion of LeaderMember Exchange Theory », Group \& Organization Management, Vol. 35, № 4, 2010, pp. 391-420.

${ }^{173}$ Lee Y-T., Reiche B-S. et Song D. : «How Do Newcomers Fit In? The Dynamics between Person-Environment Fit and Social Capital across Cultures », International Journal of Cross Cultural Management, Vol. 10, № 2, 2010, pp. 153-174.

${ }^{174}$ Taras V., Kirkman B-L. et Steel P. : « Examining the Impact of Culture's Consequences : A Three Decade, Multi-Level, Meta-Analytic Review of Hofstede's Cultural Value Dimensions », Journal of Applied Psychology, Vol. 95, N 3, 2010, pp. 405-439.
} 
culturelle de Hofstede et une variété de résultats pertinents sur le plan organisationnel. Les résultats de cette étude avaient permis aux chercheurs d'avancer que :

$\ni$ Le pouvoir prédictif des valeurs culturelles était nettement inférieur à celle des traits de personnalité et des données démographiques pour certains résultats (p. ex., rendement au travail, absentéisme, roulement de personnel) mais était significativement plus élevé pour d'autres (p. ex. engagement organisationnel, identification, comportement citoyen, attitudes liées à l'équipe, recherche de rétroaction),

- Les valeurs culturelles étaient le plus fortement liées aux émotions, suivi des attitudes, puis des comportements et enfin des performances professionnelles,

$\rightarrow \quad$ Les valeurs culturelles étaient plus liées aux résultats pour les gestionnaires (plutôt que pour les étudiants) et pour les répondants plus âgés, de sexe masculin et plus instruits,

$\ni \quad$ Les effets significativement plus forts dans des pays culturellement plus serrés que dans des pays plus lâches.

\section{Les études menées au cours de la deuxième décennie du $21^{\text {ième }}$ siècle}

L'étude de Brookes et al. ${ }^{175}$, qui avait utilisé des données provenant de 14 pays européens, cherchait à comprendre dans quelle mesure les institutions et la culture structuraient-elles le choix managérial. Les résultats de cette étude avaient indiqué que les facteurs institutionnels, et plus spécifiquement les relations de travail, ont plus de pouvoir explicatif que les facteurs culturels.

L'étude de Dizgah et al. ${ }^{176}$, qui était mené auprès de 93 PME dans la province de Guilan, avait montré que les pratiques RH de haute performance tel que la formation et la récompense n'étaient pas positivement liées à l'efficacité des entreprises, mais avec le rôle de médiateur du comportement de citoyenneté organisationnelle et de la justice procédurale, la relation était significative.

L'étude de Zaitouni et al. ${ }^{177}$, qui était menée auprès d'employés permanents à temps plein et à temps partiel (cadres et non-cadres) de cinq grandes banques privées au Koweït, avait établi que dans 50\% l'impact des pratiques RH sur l'engagement organisationnel affectif, continu et normatif des employés était confirmé et dans les 50\% restants les résultats ne soutenaient pas cette relation et ceci en raison de facteurs tels que la culture et les valeurs.

\footnotetext{
${ }^{175}$ Brookes M., Croucher R., Fenton-O'Creevy M. et Gooderham P. : «Measuringcompeting explanations of human resource management practices through the Cranet survey : cultural versusinstitutional explanations », Human Resource Management Review, Vol. 21, No 1, 2011, pp. 68-79.

${ }^{176}$ Dizgah M-R., Gilaninia S., Alipour H. et Asgari A. : «High Performance Human Resource and Corporate Entrepreneurship: the Mediating Role of Organizations Citizenship Behavior and Procedure Justice », Australian Journal of Basic and Applied Science, Vol. 5, № 3, 2011, pp. 492499.

${ }^{177}$ Zaitouni M., Sawalha N. et El Sharif A. : «The Impact of Human Resource Management Practices on Organizational Commitment in the Banking Sector in Kuwait », International Journal of Business and Management, Vol. 6, N 6, 2011, pp. 108-123.
} 
L'étude de Li et Zahra ${ }^{178}$, qui s'était appuyée sur une analyse du niveau d'activité de capital-risque pour 68 pays au cours de la période 1996-2006, avait cherché à comprendre pourquoi le niveau d'activité de capital-risque variait-il d'un pays à l'autre. Les résultats de cette étude avaient montré que les institutions formelles ont un effet positif sur le niveau d'activité de capital-risque, mais cet effet est plus faible dans les sociétés dont le degré d'évitement de l'incertitude est plus élevé et dans les sociétés plus collectivistes.

L'étude de Yang et al. ${ }^{179}$, qui avait interrogé 6509 cadres de 24 pays, avait relevé que tout en travaillant le même nombre d'heures, les employés des pays individualistes avaient signalé une charge de travail perçue plus élevée que leurs homologues des pays collectivistes et que les relations entre la charge de travail perçue et les contraintes organisationnelles avec l'insatisfaction au travail et les intentions de rotation étaient plus fortes dans les pays individualistes que dans les pays collectivistes.

L'étude Parboteeah ${ }^{180}$, qui était effectuée auprès de 30974 individus de 25 pays, avait cherché à comprendre les différences transnationales dans les valeurs du travail en examinant les effets de la post-industrialisation sur les valeurs du travail. Les résultats avaient montré que la postindustrialisation est liée négativement aux valeurs de travail extrinsèques et intrinsèques. Cependant, l'étude avait soutenu l'affirmation fondamentale des chercheurs selon laquelle les institutions sociales sont importantes pour comprendre les différences transnationales dans les valeurs du travail. L'étude de Yim et al. ${ }_{2}^{181}$ qui était effectuée auprès de 383 étudiants au Royaume-Uni et à Taiwan, avait étudié les influences culturelles sur la formation des attitudes des consommateurs envers les marques de luxe. Les chercheurs avaient montré que la sensibilité du consommateur à l'influence interpersonnelle normative affecte les marques de luxe à travers le rôle de médiateur de la conscience de marque.

L'étude d'Azeem et al. ${ }^{182}$, qui était effectuée auprès de 260 employés travaillant dans différentes banques pakistanaises, avait révélé que le comportement de citoyenneté organisationnelle jouait un rôle médiateur partiel dans la relation entre la justice organisationnelle et la performance organisationnelle perçue et que le comportement de citoyenneté organisationnelle jouait un rôle

\footnotetext{
${ }^{178} \mathrm{Li}$, Y. et Zahra S-A. : «Formal institutions, culture, and venture capital activity : A cross-country analysis ». Journal of Business Venturing, Vol. 27, $\mathrm{N}^{\circ} 1,2012$, pp. 95-111.

${ }^{179}$ Yang L-Q., Spector P-E., Sanchez J-I., Allen T-D., Poelmans S., Cooper C-L. et Antoniou A-S. : «Individualism-collectivism as a moderator of the work demands-strains relationship : A cross-level and cross-national examination », Journal of International Business Studies, Vol.43, $\mathrm{N}^{\circ} 4$, 2012, pp. 424-443.

${ }^{180}$ Parboteeah K-P., Cullen J-B. et Paik Y. : «National differences in intrinsic and extrinsic work values : The effects of post-industrialization ». International Journal of Cross Cultural Management, Vol. 13, $\mathrm{N}^{\circ}$ 2, 2013, pp. 1-16.

${ }^{181}$ Yim Y-C-M., Sauer P-L.., Lee W-J. et Macrury I. : «Drivers of attitudes toward luxury brands : A cross-national investigation into the roles of interpersonal influence and brand consciousness », International Marketing Review, Vol. $31 \mathrm{~N}^{\circ} 4,2014$, pp. 363-389.

${ }_{182}$ Azeem M-M., Abrar M., Bashir M. et Zubair A. : "Impact of Organizational Justice and Psychological Empowerment on Perceived Organizational Performance: The Mediating Role of Organizational Citizenship Behaviour », American Journal of Industrial and Business Management, Vol.5 N ${ }^{\circ}$, May 25, 2015, pp. 272-280.
} 
médiateur complet dans la relation entre l'autonomisation psychologique et la performance organisationnelle perçue.

L'étude de Farndale et Murrer ${ }^{183}$, qui avait combiné de nombreux résultats de recherche existants avec les situations réelles de fonctionnement de l'entreprise, avait constaté que les méthodes de motivation les plus appropriées étaient différentes pour les employés de différents milieux culturels et fournissait des références et des suggestions combinant des facteurs assez variés comme : l'importance du travail, la hiérarchisation des besoins, la dichotomie des facteurs internes et externes ainsi que la perception des mécanismes de récompense et de punition, pour la gestion interculturelle des RH dans les entreprises internationales.

L'étude de Gunkel et al. ${ }^{184}$, qui s'était basée sur un ensemble de données multinational comprenant 1527 personnes issues de dix groupes culturels différents, avait montré que l'évitement de l'incertitude et l'orientation à long terme influençaient les préférences pour les styles de gestion des conflits. De plus, les auteurs avaient constaté que le collectivisme a un effet négatif direct sur la préférence pour un style dominant et que la distance de pouvoir a un effet positif direct sur la préférence pour un style d'évitement.

L'étude de Hofman et Newman ${ }^{185}$, qui était menée auprès de 280 employés de cinq entreprises manufacturières orientées vers l'exportation en Chine, avait constaté que les perceptions des employés des pratiques de responsabilité sociale des entreprises envers les parties prenantes internes étaient liées positivement à leur engagement organisationnel. En revanche, la perception qu'avaient les employés des pratiques de responsabilité sociale des entreprises vis-à-vis des parties prenantes externes avait eu un impact non significatif ou marginalement significatif sur l'engagement organisationnel. De plus, les orientations collectivistes et masculines des employés avaient modéré cette relation.

L'étude de Predrag et al. ${ }^{186}$ avait pour objectif d'attirer l'attention sur la place importante de la culture organisationnelle dans la relation entre les pratiques RH et la performance organisationnelle. A ce sujet, selon cette étude, la culture organisationnelle influait sur les attitudes et le comportement de chaque employé et par conséquent le potentiel de travail des individus et des équipes de travail et de là la performance organisationnelle.

\footnotetext{
${ }^{183}$ Farndale E. et Murrer I. : «Job Resources and Employee Engagement A Cross-national Study », Journal of Managerial Psychology, Vol. 30, 2015, pp. 610-626.

${ }^{184}$ Gunkel M., Schlaegel C. et Taras V. : «Cultural Values, Emotional Intelligence, and Conflict Handling Styles : A Global Study ». Journal of World Business, Vol. 51, $\mathrm{N}^{\circ}$ 4, pp. 568-585.

${ }^{185}$ Hofman P-S. et Newman A. : «The impact of perceived corporate social responsibility on organizational commitment and the moderating role ofcollectivism and masculinity : evidence from China », The International Journal of Human Resource Management, Vol. 25, $\mathrm{N}^{\circ}$ 5, pp. 631-652.

${ }^{186}$ Predrag R., Aleksandar D., Momcilo D., Nebojsa D. et Zoran N. : «Increasing Organizational Performance By HRM», Tehnicki Vjesnik, Vol. 22, No 2, April 2015, pp. 263-269.
} 
L'étude d'Abu Keir ${ }^{187}$, qui était menée auprès de 300 employés universitaires et administratifs employés par cinq universités privées bahreïnies, avait montré qu'il existait une relation directe entre les pratiques RH et les différentes perceptions des employés de la performance organisationnelle et surtout l'existence d'un effet médiateur positif de la culture organisationnelle principalement la fidélisation et l'engagement des employés.

L'étude de Hazril et Zulkafli ${ }^{\mathbf{1 8 8}}$, qui était menée auprès de 132 entreprises manufacturières publiques malaisiennes de produits de consommation, avait montré qu'une culture organisationelle encourageant l'intégration de tous les employés augmentait le potentiel de travail des individus et des équipes et, par conséquent, dans l'ensemble, elle influait sur les résultats de l'organisation.

L'étude de Kariithi et Ogutu ${ }^{189}$, qui était menée auprès des salariés de Safaricom $\operatorname{Ltd}^{190}$, avait pu démontrer que les facteurs personnels et surtout les valeurs et la culture de Safaricom basées sur le bon service à la clientèle, la satisfaction des employés, la flexibilité et la résolution rapide des problèmes avaient permis en premier lieu de réaliser un ajustement horizontal et vertical des pratiques RH et en suite l'amélioration de la performance organisationnelle de l'entreprise étudiée.

L'étude de Rod et al. ${ }^{191}$, qui était menée auprès de 2424 personnes dans 120 organisations situées dans quatre pays (Suède, Japon, Autriche et Allemagne), avait révélé des différences significatives dans les effets des pratiques $\mathrm{RH}^{192}$ au niveau organisationnel sur l'engagement organisationnel individuel à travers les cultures pour la formation et le travail d'équipe et un soutien partiel des différences entre les cultures pour les effets l'implication des employés dans la prise de décision.

L'étude de Rana et Malik ${ }^{193}$, qui était effectuée auprès d'un échantillon d'employés des fournisseurs de services de télécommunications mobiles opérant au Punjab (Pakistan), avait montré que les cinq pratiques RH suivantes : la sélection, la formation, la rémunération, l'évaluation de la performance et la participation des employés, étaient liées de façon significative et positive au rendement de l'organisation. En plus, la modération par l'application des principes islamiques (L'éthique islamique du travail) a été jugée positive et que son ampleur avait généralement affiché une tendance à la baisse avec une augmentation du niveau d'application.

\footnotetext{
${ }^{187}$ Abu Keir Mohammed Youssif : «Staff Perceptions of how HRMP influence Organisational Performance: Mediating roles of Organisational Culture, Employees' Commitment and Employee Retention in Bahrain Private Universities », Thèse de Doctorat en Philosophie soutenue en 2016 à la Cardiff School of Management, Cardiff Metropolitan University.

${ }^{188}$ Hazril I-I. et Zulkafli A-H. : «Corporate governance, HRMP and organizational performance », International Journal of Business and Economic Sciences Applied Research, Vol. 9, N 1, 2016, pp. : 7-17.

${ }^{189}$ Kariithi J-W. et Ogutu M-O. : «Impact of Strategic HRMP on Organizational Performance (A Case Study of Safaricom)», Human Resource and Leadership Journal, Vol. 1, $\mathrm{N}^{\circ} 1,2016$, pp. 1-18.

${ }^{190} \mathrm{C}$ 'est un opérateur de réseau mobile au Kenya

${ }^{191}$ Rode J-C., Huang X. et Flynn B. : «A cross-cultural examination of the relationships among human resource management practices and organisational commitment : An institutional collectivism perspective », Human Resource Management Journal, Vol. 26, N 4, 2016, pp. 471-489. ${ }^{192}$ Les pratiques RH retenues dans cette étude étaient : la formation et l'implication des employés dans la prise de décision.

${ }^{193}$ Rana M-H. et Malik M-S. : «Impact of human resource (HR) practices on organizational performance: Moderating role of Islamic principles », International Journal of Islamic and Middle Eastern Finance and Management, Vol. 10, № 2, 2017, pp.186-207.
} 
L'étude de Koster et Gutauskaite ${ }^{194}$, qui avait utilisé des données des salariés de 25 pays européens, voulait, en explorant le rôle de la culture nationale, expliquer les variations observées dans la relation entre les pratiques RH et l'engagement organisationnel dans les 25 pays étudiés. Les résultats avaient montré que le lien entre autonomie et engagement était modéré par l'individualisme et que les effets d'autonomie et de valorisation des compétences étaient modérés par la distance de pouvoir.

Dans l'ensemble, toutes les études répertoriées avaient pu valider empiriquement soit le rôle modérateur ou de médiation de la culture dans l'impact des pratiques RH sur la performance des organisations.

En résumé, les résultats présentés par les différents auteurs constituent en eux-mêmes des pistes intéressantes de recherche ainsi que des recommandations quant à la réalisation d'études semblables.

Parmi les études qui ont pris le challenge de tester le lien entre les pratiques RH et la performance au sein des organisations marocaines, nous pouvons citer celle effectuée en 2015 par El Adraoui H. ${ }^{195}$. Cette étude effectuée auprès de 92 entreprises marocaines, a permis, à travers un modèle configurationnel, d'étudier les effets de la GRH sur la performance liée à la rentabilité. Les résultats de ce travail attestent, d'un côté, que plus les pratiques RH développées par les entreprises sont cohérentes entre elles, meilleures sont les performances liées à la rentabilité. D'un autre côté, cette étude a pu conclure que l'effet regroupé des pratiques RH explique davantage la performance des grandes entreprises au Maroc que ne peut le faire la somme des effets individuels de ces pratiques.

- En 2014, L'étude d'Azouzou ${ }^{196}$ avait cherché à déterminer si la variable culturelle pouvait expliquer certains comportements des salariés marocains et comment mobiliser ces derniers pour gérer la qualité au bénéfice de l'entreprise et partant celui de la société. Selon l'auteur, les facteurs culturels de compétitivité sont à prospecter dans les ingrédients suivants : les valeurs la culture chevaleresque, de dignité et de solidarité. Les deux premières sont indispensables pour le dépassement de soi (besoin d'accomplissement de Maslow), la troisième est indispensable pour le management de groupe (cercles de qualité, groupes amélioration qualité). Au final, l'auteur s'était forcé de constater que le potentiel culturel national n'est, cependant, pas encore suffisamment mobilisé au service du développement pour un épanouissement des composantes du trinôme : société, groupe et individu.

\footnotetext{
${ }^{194}$ Koster F. et Gutauskaite D. : «HRM-Culture fit : Why the link between human resource practices and commitment varies across countries », Dynamic Relationships Management Journal, Vol. 8, No 1, May 2019, pp. 13-27.

${ }^{195}$ El Adraoui H. : «Effets de la GRH sur la performance: validation du modèle configurationnel auprès d'un échantillon de 92 entreprises au Maroc », Question (s) de management, Vol. 3, 2015, pp. 43-56.

${ }^{196}$ Azouzou H. : «La dimension culturelle de la qualité », Albayane le 05 - $01-2014$
} 
- En 2015, l'étude de Moutaouakil ${ }^{197}$, qui était menée auprès de 70 grandes entreprises marocaines, avait comme objectif de vérifier empiriquement l'impact du Contrôle de Gestion Sociale sur la performance économique. Les résultats de cette étude avaient indiqué que, plus l'entreprise est performante socialement, plus elle le sera sur le plan économique et que la majorité des pratiques RH avaient un impact positif sur la performance individuelle et collective. En plus, un système de Contrôle de Gestion Sociale s'était avéré pertinent dans une démarche de pilotage social des grandes entreprises marocaines.

- En 2015, L'étude de Laalou et El Guermai ${ }^{198}$ s'était penchée sur une vision quantitative des pratiques RH, sur le degré d'implantation des pratiques RH et sur l'impact de celles-ci sur la performance d'une société spécialisée dans l'embouteillage d'eau «Société Source Marrakech ». En faisant appel à des indicateurs d'évaluation des principales pratiques RH (Emploi, Appréciation du personnel, Formation continue, GPEC et Développement des RH) et l'influence de celle-ci sur la performance financière, économique et sociale de l'entreprise.

- En 2017, Maghni A. et Amine A., ont cherché à travers leur étude ${ }^{199}$ de mesurer l'effet de la socialisation des nouvelles recrues d'une banque marocaine sur leur engagement. Au final, cette étude a permis de mettre en évidence l'existence d'un effet positif et significatif des tactiques sociales sur l'engagement organisationnel, tant au niveau de l'engagement calculé qu'au niveau de l'engagement affectif. Les interactions avec les membres expérimentés améliorent l'intégration sociale des nouvelles recrues, d'autant plus que leur identité individuelle est respectée. «En effet, lorsque la nouvelle recrue a de bons rapports avec ses collègues et ses supérieurs, et qu'elle est bien informée de ce qu'elle doit faire pour être appréciée positivement, cela ne peut avoir que des effets positifs sur l'engagement, tant que les tactiques organisationnelles mise en cuvre sont de nature sociale $»^{200}$.

- En 2018, dans leur ouvrage, Dlimi et Alami ${ }^{201}$ avaient stipulé que le maintien de la performance des équipes n'est pas une chose aisée dans le cadre de la PME marocaine et surtout face à un environnement perturbé et sous haute pression concurrentielle. Les auteurs avaient soutenu que la recherche du compromis entre les acteurs peut s'avérer coûteuse pour ces

\footnotetext{
${ }^{197}$ Moutaouakil A. : «L'impact du Contrôle de Gestion Sociale sur la Performance Economique : Cas des Grandes Entreprises Marocaines », Thèse pour l'obtention de Doctorat en Sciences Economiques et Gestion, soutenue en 2015 à la FSJES Université Sidi Mohamed Benabdellah - Fès. ${ }^{198}$ Laalou A. et El Guermai L. : «Mesurer l'impact du Management des Ressources Humaines sur la Performance de l'entreprise : Cas de la société Source Marrakech », International Journal of Innovation and Applied Studies, Vol. 13, N² 2, 2015.

${ }_{199}$ Maghni A. et Amine A. : «ocialisation Organisationnelle Et Engagement Des Nouvelles Recrues D'une Banque Marocaine : Etude Des Effets Spécifiques Par La Méthode PLS », Revue Marocaine de Management Logistique et Transport, N², 2017, pp. $239-272$.

${ }^{200}$ Maghni A. et Amine A. : «Socialisation Organisationnelle Et Engagement Des Nouvelles Recrues D'une Banque Marocaine : Etude Des Effets Spécifiques Par La Méthode PLS », Revue Marocaine de Management Logistique et Transport, N², 2017 , pp. $239-272$.

${ }^{201}$ Dlimi S. et Alami F-Z. : «Performance des équipes : cas des PME marocaines », Editions L'Harmattan, 2018.
} 
organisations et ils ont présenté une vision sur les méthodes et stratégies permettant de garantir la performance durable des équipes particulièrement au sein des PME familiales marocaines.

- En 2019, l'étude de Yassine et Côme ${ }^{202}$, qui était effectuée auprès d'un échantillon de 75 techniciens et agents de maîtrise, avait analysé les relations entre la nature de l'attachement d'un employé à l'égard de son organisation et la performance individuelle au travail. Les résultats de cette étude avaient établi l'existence de relations positives entre certaines dimensions de l'implication organisationnelle et la performance dans la tâche. En revanche, le degré d'association est sensiblement différent selon la nature de l'attachement.

- En 2020, l'étude de Karim, Komat et Koubaa ${ }^{203}$, qui était effectuée auprès d'un échantillon de 107 grandes entreprises opérantes au Maroc, avait comme objectif de relever les associations simultanées entre les systèmes $\mathrm{RH}^{204}$, les stratégies d'affaire et les deux indicateurs de la performance «sociétale/environnementale ${ }^{205}$. En se basant sur les principes de l'approche configurationnelle, cette étude avait montré que la cohérence interne entre les systèmes RH, ainsi que leur cohérence externe avec la stratégie d'affaires, peuvent constituer un important levier d'amélioration de la performance sociétale/environnementale.

$\mathrm{Au}$ final et sans prétendre à l'exhaustivité, cette revue de littérature théorique et empirique sur les problématiques des pratiques $\mathrm{RH}$, culture et performance des organisations, nous pouvons avancer qu'il y a toujours besoins de d'autres études abordant les différentes problématiques relevant de ce domaine surtout dans les pays en voie de développement. Dans ce sens nous allons reprendre la sitation d'El Adraoui H. : «En dépit de nombreuses années de recherche, la question du lien RH-performance est loin d'être tranchée. Le regard porté par les managers marocains sur le lien RH-Performance est encore hésitant. Pour une raison simple : ils ne le maitrisent pas ${ }^{206}$.

\section{BIBLIOGRAPHIE}

[1] Abu Keir Mohammed Youssif : «Staff Perceptions of how HRMP influence Organisational Performance: Mediating roles of Organisational Culture, Employees' Commitment and Employee Retention in Bahrain Private Universities », Thèse de Doctorat en Philosophie soutenue en 2016 à la Cardiff School of Management, Cardiff Metropolitan University.

[2] Aït Razouk A. : «GSRH : recherche théorique et empirique sur la durabilité de la relation entre stratégie RH et performance », Thèse soutenue en 2007 à Nancy 2.

[3] Ait Razouk A. et Bayad M. : « GRH mobilisatrice et performance des PME : quelle causalité ? », Revue de GRH, Vol. 4, N 82, 2011, pp. 3-18.

\footnotetext{
${ }^{202}$ Yassine A. et Côme T. : «La nature de l'attachement entre l'employé et l'organisation, vecteur de la performance individuelle ?», Revue des Etudes Multidisciplinaires en Sciences Economiques et Sociales, Vol. 4, N 1, 2019.

${ }^{203}$ Karim S., Komat A. et Koubaa S. : «Les systèmes de gestion des ressources humaines et la performance sociétale/environnementale de la grande entreprise au Maroc», XXIXe Conférence Internationale de Management Stratégique, Juin 2020.

${ }^{204}$ Le système RH était conçu sous forme d'un ensemble de pratiques RH cohérentes entre elles

${ }^{205}$ La performance sociétale/environnementale était mesurée à travers l'« engagement sociétal » et la « présence d'une stratégie environnementale ».

${ }^{206}$ El Adraoui H., Professeur à l'ISCAE et consultante en RH : selon une étude sur le lien RH-Performance menée auprès de 92 entreprises nationales et multinationales au Maroc « GRH : Un toolkit pour les bonne pratiques » publiée dans l’Economiste du 14.12.2017.
} 
[4] Alatailat M., Elrehail H. et Okechukwu Lawrence Emeagwali : «High performance work practices, organizational performance and strategic thinking : A moderation perspective », International Journal of Organizational Analysis, 2019.

[5] ALDamoe F-M-A., Yazam M. et Bin Ahmid K. : « The Mediating Effect of HRM Outcomes (employee retention) on the Relationship between HRM Practices and Organizational Performance », International Journal of Human Resource Studies, Vol. 2, $\mathrm{N}^{\circ}$ 1, pp. 75-88.

[6] Al-Emadi M-A-S. et Marquardt M-J. : «Relationship between employees' beliefs regarding training benefits and employees' organizational commitment in a petroleum company in the State of Qatar », International Journal of Training and Development, Vol. 11, $\mathrm{N}^{\circ}$ 1, February 2007, pp. 49-60.

[7] Allouche J., Charpentier M. et Guillot-Soulez C. : « GRH et Performances de l'entreprise : l'improbable lien ? Un panorama des études académiques sur l'interaction performances sociales/performances économiques et financières », XVe Congrès annuel de l'AGRH, Montréal, tome 1, 2004, pp. 31-58.

[8] Arcand G., Arcand M., Chrétien L. et Tellier G. : «Impacts des pratiques de gestion des ressources humaines sur la performance organisationnelle des entreprises de gestion de projets », Revue internationale sur le travail et la société, Vol. 3, $\mathrm{N}^{\circ} 1,2005$, pp. 107-128.

[9] Arcand M., Arcand G., Bayad M. et Fabi B. : «Systèmes De Gestion Des Ressources Humaines Et Performance Organisationnelle », Annals of Public and Cooperative Economics, Vol. 75, N 3, 2004, pp. 497-524.

[10] Arcand M., Arcand G., et Bayad M. : «Gestion stratégique des ressources humaines et performance de la firme: une validation de l'approche de la contingence », Revue internationale des relations de travail, Vol. 2, No. 2, 2004, pp. 74-93.

[11] Arnulf J-K. et Larsen K-R. : «Culture Blind Leadership Research : How Semantically Determined Survey Data May Fail to Detect Cultural Differences », Frontiers in Psychology, Vol. 11, N 176, 2020, pp. 1-18.

[12] Athos A-G. et Pascale R-T. : « Le management est-il un art japonais ? », Paris, Les Éditions d'organisation, 1984.

[13] Azeem M-M., Abrar M., Bashir M. et Zubair A. : «Impact of Organizational Justice and Psychological Empowerment on Perceived Organizational Performance: The Mediating Role of Organizational Citizenship Behaviour », American Journal of Industrial and Business Management, Vol.5 N 5, May 25, 2015, pp. 272-280.

[14] Azouzou H. : « La dimension culturelle de la qualité », Albayane le 05 - 01 - 2014Yassine A. et Côme T. : « La nature de l'attachement entre l'employé et l'organisation, vecteur de la performance individuelle?», Revue des Etudes Multidisciplinaires en Sciences Economiques et Sociales, Vol. 4, N 1, 2019.

[15] Bakotić D. : «Relationship between job satisfaction and organisational performance », Economic Research, Ekonomska Istraživanja, Vol. 29, $\mathrm{N}^{\circ}$ 1, 2016, pp. 118-130.

[16] Bamel U., Budhwar P., Stokes P. et Paul H. : « Dimensions of role efficacy and managerial effectiveness : evidence from India », Journal of Organizational Effectiveness : People and Performance, Vol. 4, N 5, 2017, pp. $218-237$.

[17] Bandibeno I-K. et Ndongo J-C-A : «Pratiques de gestion des ressources humaines et performance sociale des collectivités territoriales décentralisées au Cameroun », Mondes en développement, Vol. 2, N 178, 2017, pp. 139-154.

[18] Barney J. : « Firm Resources and Sustained. Competitive Advantage », Texas A\&M University, Vol. 17, N 1, 1991, pp. 99-120.

[19] Bartel A. : «Relating career stage to attitudes towards HR practices and commitment : Evidence of interaction effects ?», European Journal of Work and Organizational Psychology, Vol. 13, N 4, 2004, pp. 417-446.

[20] Becker B. et Huselid M-A. : «High Performance Work Systems and Firm Performance : A Synthesis of Research and Managerial Implications », Research in Personnel and Human Resource Management, Vol. 16, 1998, pp. 53-101.

[21] Bercu A-M. : « The Impact Of HRMP on SMEs Performance In Romania », Anale, Seria Stiinte Economice, Timisoara, Faculty of Economics, Tibiscus University in Timisoara, Vol. 0, May 2013, pp. 44-52.

[22] Bernard M. : «L'effet des pratiques de ressources humaines sur la performance sociale des employés dans un contexte de culture nationale », Thèse de Doctorat ès Sciences de Gestion soutenue en 2009, Ecole de Management de Strasbourg en cotutelle avec l'Université d'Ottawa.

[23] Bouckenooghe D., Raja U, Butt A-N., Abbas M. et Bilgrami S. : « Unpacking the curvilinear relationship between negative affectivity, performance, and turnover intentions: The moderating effect of time-related work stress », Journal of Management \& Organization, Vol. 1, 2016, pp. 1-19.

[24] Bowen D-E. et Ostroff C. : « Understanding HRM-Firm Performance Linkages : The Role of the "Strength" of the HRM System », The Academy of Management Review, Vol. 29, N², April 2004, pp. 203-221.

[25] Brookes M., Croucher R., Fenton-O’Creevy M. et Gooderham P. : « Measuringcompeting explanations of human resource management practices through the Cranet survey : cultural versusinstitutional explanations », Human Resource Management Review, Vol. 21, N 1, 2011, pp. 68-79.

[26] Caligiuri P-M., Colakoglu S., Cerdin J-L. et Kim M-S. : «Examining cross-cultural and individual differences in predicting employer reputation as a driver of employer attraction », International Journal of Cross Cultural Management, Vol. 10, $\mathrm{N}^{\circ} 2,2010$, pp. 137-151.

[27] Carriere J. et Barrette J. : « GRH et performance de la firme à capital intellectuel élevé : une application des perspectives de contingence et de configuration », Canadian Journal of Administrative Sciences, Vol. 22, N 4, pp. 302-315. 
[28] Cassoni A. et Labadie G-J. : «The impact of HRP and labor relations on organizational performance in Uruguay : an empirical test », Document de recherche, $N^{\circ}$ 83, Décembre 2012, Universidad ORT Uruguay, Faculté d'Administration et des Sciences Sociales.

[29] Chakraborty D. et Biswas W. : «Evaluating the impact of human resource planning programs in addressing the strategic goal of the firm : An organizational perspective », Journal of Advances in Management Research, Vol. 16, N 5, November 2019, pp. 659-682.

[30] Charles-Pauvers B., Urbain C. et Le Quentrec : «Pratiques De GRH Et Performance Commerciale : Le cas d'un centre d'appels », Revue française de gestion, $\mathrm{N}^{\circ} 176,2007$, pp. 15-33.

[31] Chew J. et Chan C-C-A. : «Human resource practices, organizational commitment and intention to stay », International Journal of Manpowr, Vol. 29, $\mathrm{N}^{\circ}$ 6, 2008, pp. 503-522.

[32] Cho S., Woods R-H., Jang S-C. et Erdem M. : « Measuring the impact of human resource management practices on hospitality firms' performances », International Journal of Hospitality Management, Vol. 25, N², 2006, pp. $262-277$.

[33] Chordiya R., Sabharwal M. et Goodman D. : «Afective organizational commitment and job satisfaction : A cross-national comparative study », Public Administration, Vol. 95, № 1, 2017.

[34] Chourouk S-M. : «Impacts des pratiques de rémunérations variables sur la performance organisationnelle et financière de certaines PME manufacturières », Mémoire, Université du Québec à Trois-Rivières, Septembre 2006.

[35] Chrétien L., Arcand G., Tellier G. et Arcand M. : « Impacts des pratiques de GRH sur la performance organisationnelle des entreprises de gestion de projets », Revue Internationale sur le Travail et la Société, Vol. 3, N 1, 2005, pp. $107-126$.

[36] Chukwuka E-J. et Nwakoby N-P. : «Effect of Human Resource Management Practiceson Employee Retention and Performance in Nigerian Insurance Industry », World Journal of Research and Review, Vol. 6, N 4, April 2018, pp. $27-41$.

[37] Collings D-G., Demirbag M., Mellahi K. et Tatoglu E. : « Strategic orientation, human resource management practices and organizational outcomes : Evidence from Turkey », The International Journal of Human Resource Management, Vol. 21, $\mathrm{N}^{\circ}$ 14, November 2010, pp. 2589-2613.

[38] Colot O., Dupont C. et Volral M. : «Influence des pratiques de GRH sur la performance sociale des entreprises familiales », 2ièmes journées Georges Doriot, 15 et 16 Mai 2008.

[39] Colvin A., Batt R. et Keefe J. : « The Impact of Employee Voice and Compliance Mechanisms on Absenteeism, Discipline, and Turnover », CAHRS Working Paper, Ithaca, NY : Cornell University, School of Industrial and Labor Relations, Center of Advanced Human Resource Studies, 2005, http://digitalcommons.ilr.cornel.edu/cahrswp/281/ Delery J-E. et Doty DH. : «Modes of Theorizing in Strategic Human Resource Management: Test of Universalistic, Contingency, and Configurational Performance Predictions », Academy of Management Journal, Vol. 39, 1996, pp. 802-835.

[40] Combs J-G., Liu Y., Hall A. et Ketchen D. : « How Much Do High-Performance Work Practices Matter ? A Meta-Analysis of Their Effects on Organizational Performance », Personnel Psychology, Vol. 59, $\mathrm{N}^{\circ}$ 3, August 2006, pp. 501-728. https://doi.org/10.1111/j.1744-6570.2006.00045.x

[41] D'art D. et Turner T. : « Profit sharing, firm performance and union influence in selected European countries », Personnel Review, Vol. 33, N³, 2004, pp. 335-350.

[42] Datta D-K., Guthrie J-P. et Wright P. : «HRM and Labor Productivity : Does Industry Matter ?», The Academy of Management Journal, Vol. 48, N 1, February 2005. https://doi.org/10.5465/amj.2005.15993158

[43] Daud S., Abidin N., Sapuan N-M. et Rajadurai J. : « Efficient human resource deployment technique in higher education: A standpoint from Malaysia », African Journal of Business Management, Vol. 6, N²5, June 2012, pp. 7533-7547.

[44] Delaney J-T. et Huselid M-A. : « The Impact of Human Resource Management Practices on Perceptions of Organizational Performance », Academy of Management Journal, Vol. 39, $\mathrm{N}^{\circ}$ 4, November 2017. 1996

[45] Delery J-E. et Doty D-H. : « Modes of Theorizing in Strategic Human Resource Management : Test of Universalistic, Contingency, and Configurational Performance Predictions », Academy of Management Journal, Vol. 39, 1996, pp. 802835 .

[46] Dizgah M-R., Gilaninia S., Alipour H. et Asgari A. : «High Performance Human Resource and Corporate Entrepreneurship: the Mediating Role of Organizations Citizenship Behavior and Procedure Justice », Australian Journal of Basic and Applied Science, Vol. 5, N 3, 2011, pp. 492-499.

[47] Dlimi S. et Alami F-Z. : «Performance des équipes : cas des PME marocaines », Editions L'Harmattan, 2018.

[48] El Adraoui H. : «Effets de la GRH sur la performance: validation du modèle configurationnel auprès d'un échantillon de 92 entreprises au Maroc », Question (s) de management, Vol. 3, 2015, pp. 43-56.

[49] El Adraoui H., Professeur à l'ISCAE et consultante en RH : selon une étude sur le lien RH-Performance menée auprès de 92 entreprises nationales et multinationales au Maroc «GRH : Un toolkit pour les bonne pratiques » publiée dans l'Economiste du 14.12.2017.

[50] Elrehail H., Harazneh I., Abuhjeeleh M., Alzghoul A., Alnajdawi S. et Hussein Ibrahim H-M. : « Employee satisfaction, human resource management practices and competitive advantage: The case of Northern Cyprus », European Journal of Management and Business Economics, Vol. 29, $\mathrm{N}^{\circ}$ 2, 2020, pp. 125-149.

[51] Fabi B., Lacoursière R. et Raymond L. «Impact of high-performance work systems on job satisfaction, organizational commitment, and intention to quit in Canadian organizations », International Journal of Manpower, Vol. 36, N 5, 2015, pp. $772-790$. 
[52] Fabi B., Raymond L. et Arcand M. : «Les PME les plus performantes se distinguent-elles par leurs pratiques de GRH ? », 7ième Congrès International Francophone en Entrepreneuriat et PME, Octobre 2004, Montpellier.

[53] Farndale E. et Murrer I. : « Job Resources and Employee Engagement A Cross-national Study », Journal of Managerial Psychology, Vol. 30, 2015, pp. 610-626.

[54] Fiorito J., Bozeman D-P., Young A. et Meurs J-A. : «Organizational commitment, human resource practices, and organizational characteristics », Journal of Managerial Issues, Vol. 19, $\mathrm{N}^{\circ}$ 2, 2007, pp. 186-207.

[55] Feitosa J., Grossman R. et Salazar M. : «Debunking key assumptions about teams : The role of culture », American Psychologist, Vol. 73, $\mathrm{N}^{\circ}$ 4, 2018, pp. 376-389.

[56] Gaafar M-A. : «The Impact of HRMP on Organizational Performance in Saudi Banking Sector », European Journal of Business and Management, Vol. 4, N21, 2012, pp. 188-196.

[57] Gadelrab H-F., Alkhadher O., Aldhafri S., Almoshawah S., Khatatba Y., Zine El Abiddine F., Alyetama M., Elmsalak S., Tarboush N. et Slimene S. : «Organizational Justice in Arab Countries: Investigation of the Measurement and Structural Invariance », Cross-Cultural Research, Vol. 54, $\mathrm{N}^{\circ}$ 1, 2020, pp. 3-27.

[58] Gagnon O. et Arcand G. : «Les pratiques de GRH comme catalyseur de la performance organisationnelle », Revue internationale sur le travail et la société, Vol. 9, $\mathrm{N}^{\circ} 2,2011$, pp. 1-23.

[59] García-Carbonell N., Martín-Alcázar F. et Sánchez-Gardey G. : « Understanding the HRM-Performance Link : A Literature Review on the HRM Strategy Formulation Process », International Journal of Business Administration, Vol. 5, $\mathrm{N}^{\circ}$ 2, 2014, pp. 71-81.

[60] Gellatly I-R., Hunter K-H., Currie L. et Irving P-G. : « HRM practices and organizational commitment profiles », The International Journal of Human Resource Management, Vol. 20, $\mathrm{N}^{\circ}$ 4, 2009.

[61] Giauque D., Barbey V. et Duc N.: «Les leviers de la performance individuelle et collective dans les organisations publiques suisses : l'importance d'un pilotage participatif», Revue française d'administration publique, Vol. 4, 2008, pp. 785-798.

[62] Giauque D., Resenterra F. et Siggen M. : « The relationship between HRM practices and organizational commitment of knowledge workers. Facts obtained from Swiss SMEs », Human Resource Development International, Vol. 13, $\mathrm{N}^{\circ}$ 2, 2010 , pp. 185-205.

[63] Gleibs I-H. et Alvarado L-A. : "The impact of non-standard work arrangements and communication climate on organisational and team identification and work-related outcomes amongst millennial in Chile and the UK». Social Psychological Bulletin, Vol. 14, N 3, 2019, pp. 1-32.

[64] Green K-W., Wu C., Whitten D. et Medlin B. : «The impact of SHRM on firm performance and HR professionals work attitude and work performance », The International Journal of Human Resource Management, Vol. 17, N 4, 2006, pp. 559578.

[65] Guerrero S. et Barraud-Didier V. : «High-involvement practices and performance of French firms », The International Journal of Human Resource Management, Vol. 15, N 8, 2004, pp. 1410-1425.

[66] Gunkel M., Schlaegel C. et Taras V. : «Cultural Values, Emotional Intelligence, and Conflict Handling Styles : A Global Study ». Journal of World Business, Vol. 51, $\mathrm{N}^{\circ} 4$, pp. 568-585.

[67] Hajro A. et Pudelko M. : «An analysis of core-competences of successful multinational team leaders », International Journal of Cross Cultural Management, Vol. 10, № 2, 2010, pp. 175-194.

[68] Hartog D-N-D. et Verburg R-M. : « High performance work systems, organisational culture and firm effectiveness », Human Resource Management Journal, Vol. 14, N 1, 2004, pp. 55-78.

[69] Hazril I-I. et Zulkafli A-H. : «Corporate governance, HRMP and organizational performance », International Journal of Business and Economic Sciences Applied Research, Vol. 9, N 1, 2016, pp. : 7-17.

[70] Hoch J-E. et Kozlowski S-W-J. : « Leading Virtual Teams : Hierarchical Leadership, Structural Supports, and Shared Team Leadership ». Journal of Applied Psychology, Vol. 99, N 3, 2014, pp. 390-403.

[71] Hofman P-S. et Newman A. : «The impact of perceived corporate social responsibility on organizational commitment and the moderating role ofcollectivism and masculinity : evidence from China », The International Journal of Human Resource Management, Vol. 25, $\mathrm{N}^{\circ}$ 5, pp. 631-652.

[72] Hounkou E. : «Les pratiques de gestion des ressources humaines et les performances des entreprises Béninoises : une analyse par la méthode de corrélation canonique ». Revue Internationale sur le Travail et la Société, Vol. 9, N 1, 2011, pp. $17-40$.

[73] Hunter M-G., Tan F-B. et Tan B-C.: «Voluntary turnover of information systems professionals : A cross-cultural investigation », Journal of Global Information Management, Vol. 16, $\mathrm{N}^{\circ}$ 4, 2008, pp. 46-66.

[74] Huselid M-A., Jackson S-E. et Schuler R-S. : « Technical and strategic human resource management effectiveness as determinants of firm performance », Academy of Management Journal, Vol. 40, $\mathrm{N}^{\circ}$ 1, 1997, pp. 171-188.

[75] Iyad Mohammad Ali Khashman et Aysar Mohammad Khashman : «The Impact of Human Resource Information System (HRIS) Applications on Organizational Performance (Efficiency and Effectiveness) in Jordanian Private Hospitals », Journal of Management Research, Vol. 8, ํ3, 2016, pp. 31-44. 
[76] Jeong D-Y. et Choi M. : « The impact of high-performance work systems on firm performance : The moderating effects of the human resource function's influence », Journal of Management \& Organization, Vol. 22, N 3, May 2016, pp. 328-348.

[77] Junaid D., Yadav A., Afzal F., Shah I-A., Shanmugam B., Jonkman M., Azam S. et De Boer F. : « The Configurations of Informal Institutions to Promote Men's and Women's Entrepreneurial Activities », Frontiers in Psychology, Vol. 11, Article 1909, 2020, pp. 1-16.

[78] Kariithi J-W. et Ogutu M-O. : « Impact of Strategic HRMP on Organizational Performance (A Case Study of Safaricom) », Human Resource and Leadership Journal, Vol. 1, N 1, 2016, pp. 1-18.

[79] Karim S., Komat A. et Koubaa S. : «Les systèmes de gestion des ressources humaines et la performance sociétale/environnementale de la grande entreprise au Maroc», XXIXe Conférence Internationale de Management Stratégique, Juin 2020.

[80] Katou A-A. : « Measuring the impact of HRM on organisational performance », Journal of Industrial Engineering and Management, Vol. 1, $\mathrm{N}^{\circ} 2,2008$, p. 119-142.

[81] Khal Hamza S-H.: «The Influence of National Culture on Organizational Culture in Private and Public Sector Organizations in Iraqi Kurdistan, A Cross - Sectorial Comparison », Journal of Human Sciences, Vol. 22, N 4, 2018 , pp. 323-346.

[82] Khandekar A. et Sharma A. : «Managing human resource capabilities for sustainable competitive advantage: An empirical analysis from Indian global organisations », Education and Training, Vol. 47, N 8/9, October 2005, pp. 628-639.

[83] Kidwell R-E. et Bennett N. : « Employee propensity to withhold effort : A conceptual model to intersect three avenues of research », The Academy of Management Review, Vol. 18, N³, 1993, pp. 429-456.

[84] Kim S. et Wright P. : «Putting Strategic Human Resource Management in Context : A Contextualized Model of High Commitment Work Systems and Its Implications in China », Management and Organization Review, Vol. 7, N 1, 2011, pp. 153-174.

[85] Kooij T-A-M., Guest D., Clinton M., Knight T., Jansen P-G-W. et Dikkers J-S-E. : « How the impact of HR practices on employee wellbeing and performance changes with age », Human Resource Management Journal, Vol 23, N 1, 2013 , pp. $18-35$.

[86] Koster F. et Wittek R. : « Competition and constraint: Economic globalization and human resource practices in 23 European countries », Employee Relations, Vol. 38, N², 2016, pp. 286-303.

[87] Koster F. : «Able, willing, and knowing: The effects of HR practices on commitment and effort in 26 European countries », The International Journal of Human Resource Management, Vol. 22, № 14, 2011, pp. $2835-2851$.

[88] Koster F. et Gutauskaite D. : «HRM-Culture fit : Why the link between human resource practices and commitment varies across countries », Dynamic Relationships Management Journal, Vol. 8, N 1, May 2019, pp. 13-27.

[89] Kurtulus Yilmaz Genç : «A Research on the Impacts of Core Employees on the Performances of SME's », Sociology Mind, Vol. 4, N³, June 2014, pp. 213-220.

[90] Kuvass B. et Dysvik A. : « Perceived investment in employee development, intrinsic motivation and work performance », Human Resource Management Journal, Vol. 19, № 3, 2009, pp. 217-236.

[91] Kweku Otoo F-N. : « Human resource management (HRM) practices and organizational performance : The mediating role of employee competencies », International Journal of Management Studies, Vol. 5, N 3, July 2018, pp. 91-105.

[92] Laalou A. et El Guermai L. : «Mesurer l'impact du Management des Ressources Humaines sur la Performance de l'entreprise : Cas de la société Source Marrakech », International Journal of Innovation and Applied Studies, Vol. 13, N², 2015.

[93] Lacoursière R., Fabi B., St-Pierre J. et Arcand M. : «Impact de certaines pratiques de GRH sur la performance organisationnelle et financières des PME », 12ième congrès de l'Association Internationale de Psychologie du Travail et des Organisations (AIPTO), Louvain la Neuve, Belgique, 2002, pp. 1-7.

[94] Lacoursière R., Fabi B., St-Pierre J. et Arcand M. : «Effets de certaines pratiques de GRH sur la performance de PME manufacturières : vérification de l'approche universaliste » Revue internationale P.M.E., Vol. 18, N 2, 2005 , pp. 43-75.

[95] Lambooij M., Sanders K., Ferry K. et Zwiers M. : « Human Resource Practices and Organisational Performance : Can the HRM-Performance linkage be explained by the cooperative Behaviours of Employees ?», Management Revue, Socioeconomic Studies, Vol. 17, N³, 2006, pp. 223-240.

[96] Loo-See Beh et Leap-Han Loo : «HRM Best Practices And Firm Performance : A Universalistic Perspective Approch », Serbian Journal of Management, Vol. 8, N² 2, November 2013, pp. 155-167.

[97] Lee Y-T., Reiche B-S. et Song D. : «How Do Newcomers Fit In ? The Dynamics between Person-Environment Fit and Social Capital across Cultures », International Journal of Cross Cultural Management, Vol. 10, N² 2, 2010, pp. $153-174$.

[98] Li, Y. et Zahra S-A. : «Formal institutions, culture, and venture capital activity : A cross-country analysis ». Journal of Business Venturing, Vol. 27, $\mathrm{N}^{\circ}$ 1, 2012, pp. 95-111.

[99] Luna-Arocas R. et Camps J. : « A model of high performance work practices and turnover intentions », Personnel Review, Vol. 37, N 1, 2008, pp. 26-46.

[100] Maghni A. et Amine A.: «Socialisation Organisationnelle Et Engagement Des Nouvelles Recrues D’une Banque Marocaine : Etude Des Effets Spécifiques Par La Méthode PLS », Revue Marocaine de Management Logistique et Transport, $\mathrm{N}^{\circ} 2$, 2017, pp. 239-272. 
[102] Mc Mahan G-C., Virik M. et Wright P-M. : « Alternative theoretical perspectives for SHRM revisited : progress, problems and prospects », Research in personnel and human resources management, Supplement 4, 1999, pp. 99-122.

[103] Mehwish J., Abeera A., Aideed B. et Tania H. : « Human resource practices and organizational commitment : The mediating role of job satisfaction in emerging economy», Cogent Business \& Management, Vol. 6, $\mathrm{N}^{\circ}$ 1, May 2019. https://doi.org/10.1080/23311975.2019.1608668

[104] Meyer J-P. et Herscovitch L. : « Commitment in the workplace : toward a general model », Human Resource Management Review, Vol. 11, 2001, pp. 299-326.

[105] Mittal S., Gupta V. et Motiani M.: «Relation between human resource development climate and organisational commitment : empirical study in Indian banking sector », International Indian Journal of Culture and Business Management, Vol. 12, N² 2016, pp. 204-224.

[106] Moideenkutty U., Al-Lamki A. et Murthy Y-S-R. : « HRM practices and organizational performance in Oman », Personnel Review, Vol. 40, N 2, February 2011, pp. 239-251.

[107] Moon C., Uskul A-K. et Weick M. : « On Culture, Ethics and Hierarchy: How Cultural Variations in Hierarchical Relations Are Manifested in the Code of Ethics of British and Korean Organizations », Journal of Applied Social Psychology, Vol. 48, $\mathrm{N}^{\circ} 1,2017$, pp. 15-27.

[108] Moutaouakil A. : «L'impact du Contrôle de Gestion Sociale sur la Performance Economique : Cas des Grandes Entreprises Marocaines », Thèse pour l'obtention de Doctorat en Sciences Economiques et Gestion, soutenue en 2015 à la FSJES Université Sidi Mohamed Benabdellah - Fès.Mucelli A., Spigarelli F. et Lepore D. : « National Culture for a Participatory Time-driven Activity Based Costing : A Conceptual Framework and Research Agenda ». International Journal of Business Administration, Vol. 9, $\mathrm{N}^{\circ}$ 2, 2018, pp. 56-66.

[109] Muduli A. : «High performance work system, HRD climate and organisational performance: An empirical study», European Journal of Training and Development, Vol. 39, $\mathrm{N}^{\circ} 3,2015$, pp. 239-257.

[110] Mufeed S.A. et Gulzar L. : «Impact Of HRMP On Organizational Performance : An Emprical Study Of State Bank Of India », International Journal of Management Research, Vol. 3, $\mathrm{N}^{\circ}$ 5, 2015, pp. 286-300.

[111] Munjuri M-G. : «The Effect of HRMP Practices in Enhancing Employee Performance in Catholic Institutions of Higher Learning in Kenya », International Journal of Business Administration, Vol. 2, No 4, November 2011, pp. 189-224.

[112] Mustafa G., Glavee-Geo R., et Rice P-M. : « Teamwork orientation and personal learning: The role of individual cultural values and value congruence », Journal of Industrial Psychology, Vol. 43, 2017, pp. 14-46.

[113] Mutahi N. et Busienei J-R. : « Effect Of HMRP On Performance Of Public Universities In Kenya », International Journal of Economics, Commerce and Management, United Kingdom, Vol. 3, N 10, October 2015, pp. 696-736.

[114] Muslim A., Wan K. et Wan I. : « The impact of HMRP on performance Evidence from a public University », The TQM Journal, Vol. 26, $\mathrm{N}^{\circ} 2,2014$, pp. 125-142.

[115] Naqvi I-H. Bokhari S-H-A., Aziz S. et Kashif-ur-Rehman : «The impact of HRPM on project outcome », African Journal of Business Management, Vol. 5, $\mathrm{N}^{\circ}$ 21, 2011, pp. 8491-8499.

[116] Nassar M-A. : "Human resource management practices and organizational commitment in four and five star hotels in Egypt », Journal of Human Resources in Hospitality et Tourism, Vol. 17, $\mathrm{N}^{\circ}$ 1, 2018, pp. 1-21.

[117] Naveed Iqbal et Mansoor Ahmad: «Unveiling The E-HRM-Performance Link : Evidence From Pakistani Banking Industry », GUJR, Vol. 32, $\mathrm{N}^{\circ} 1$, June 2016, pp. 65-75.

[118] Naveed I., Mansoor A. et Allen M-C. : «Unveiling the relationship between e-HRM, impersonal trust and employee productivity », Manageùent Research Review, Vol. 42, N 7, May 2019, pp. 879-899.

[119] Ndao A. : «Effets des pratiques de GRH sur la performance économique et financière des entreprises sénégalaises : par quels mécanisme ? », Thèse de doctorat d'Etat en Sciences de Gestion soutenue en 2011 à la FASEG/UCAD, Montpellier 3.

[120] Nemli Çaliskan E. : « The Impact Of SHRM On Organizational Performance », Journal of Naval Science and Engineering, Vol. 6, $\mathrm{N}^{\circ} 2,2010$, pp. 100-116.

[121] Newman A., Thanacoody R. et Hui W. : «The impact of employee perceptions of training on organizational commitment and turnover intentions: A study of multinationals in the Chinese service sector », The International Journal of Human Resource Management, Vol. 22, No 8, 2011, pp. 1765-1787.

[122] Newman K-L. et Nollen S-D. : « Culture and Congruence : The Fit Between Management Practices and National Culture », Journal of International Business Studies, Vol. 27, 1996, pp. 753-779.

[123] Nguyen P. et Belaounia S. : « Cultural Distance and Payment Method in French Cross-Border Acquisitions », International Management, Vol. 24, $\mathrm{N}^{\circ} 1,2020$, pp. 109-126.

[124] Nongmaithem R. et Biniam K. : «The Impact of HRMP on Organizational Performance : A Study on Debre Brehan University », International Jornal of Recent Advances in Organizational Behaviour and Decision Sciences, Vol. 2, $\mathrm{N}^{\circ} 1$, 2016, pp. 643-662.

[125] Omri W. et Ghorbel-Zouari S. : «Une évaluation de la performance sociale des IMF Tunisiennes : Cas de ENDA interarabe », Revue Libanaise de Gestion et d'Economie, $N^{\circ} 4$, 2010, pp. 36-64. 
[126] Ordonez de Pablos P. et Lytras M. : «Competencies and human resource management : implications for organizational competitive advantage »? Journal of Knowledge Management, Vol. 12, $\mathrm{N}^{\circ}$ 6, October 2008, pp. 48-55. Raad G. : «L'influence de l'implication organisationnelle sur l'intention d'adhésion à l'actionnariat salarié », Thèse de doctorat en Sciences de gestion soutenue en 2006 à Caen.

[127] Paauwe J. et Boselie P. : « Human Resource Management and performance : what next ? », Human Resource Management Journal, Vol. 15, N 4, 2005, pp. 68-83.

[128] Paillé P., Chen Y., Boiral O. et Jin J. : «The Impact of HRM on Environmental Performance : An Employee-Level Study », Journal of Business Ethics, Vol. 121, N³, 2014, pp. 451 - 466.

[129] Parboteeah K-P., Cullen J-B. et Paik Y. : « National differences in intrinsic and extrinsic work values : The effects of postindustrialization ». International Journal of Cross Cultural Management, Vol. 13, N², 2013, pp. 1-16.

[130] Pare G. et Tremblay M. : «The Influence of High-Involvement Human Resources Practices, Procedural Justice, Organizational Commitment, and Citizenship Behaviors on Information Technology Professionals' Turnover Intentions »; Group et Organization Management, Vol. 32, N³, June 2007, pp. 326-357.

[131] Pati S-P. et Kumar M-P-P. : «Influencing employee attitudes through HR practices: an exploratory study in Indian IT sector », International Journal of Indian Culture and Business Management, Jan 2010, Vol. 3, N 6, pp. 607-622

[132] Paul A-K. et Anantharaman R-N. : «Influence of HRM practices on organizational commitment : A study among software professionals in India », Human Resource Development Quarterly, Vol. 15, N 1, February 2004, pp. 77-88.

[133] Payne S-C. et Huffman A-H. : «A Longitudinal Examination of the Influence of Mentoring on Organizational Commitment and Turnover », The Academy of Management Journal, Vol. 48, N 1, February 2005, pp. 158-168.

[134] Pellegrini E-K., Scandura T-A. et Jayaraman V. : «Cross-Cultural Generalizability of Paternalistic Leadership : An Expansion of Leader-Member Exchange Theory », Group \& Organization Management, Vol. 35, No 4, 2010, pp. $391-420$.

[135] Pfeffer J. : « Competitive advantage through people: Unleashing the power of the work force », Boston : Harvard Business School Press, 1994.

[136] Pilar G-N., Talavera-Escribano E., Rosario Zurriaga-Lloréns et Lucía . Llinares-Insa : « Culture, Work, and Subjective Well-Being: The Role of LMX and Resilience in Spanish and Chinese Cultures », International Journal of Environmental Research and Public Health, Vol. 16, N²4, 2019, pp. 1-16.

[137] Predrag R., Aleksandar D., Momcilo D., Nebojsa D. et Zoran N. : « Increasing Organizational Performance By HRM », Tehnicki Vjesnik, Vol. 22, N² ${ }^{\circ}$ April 2015, pp. 263-269.

[138] Raja U., Javed Y. et Abbas M. : «A Time Lagged Study of Burnout as a Mediatorin the Relationship Between Workplace Bullying and Work-Family Conflict », International Journal of Stress Management, Vol. 25, N 4, 2018, pp. $377-390$.

[139] Ramaprasad B-S., Prabhu K-N., Lakshminarayanan S. et Pai Y-P.: «Human resource management practices and organizational commitment : a comprehensive review (2001-2016) », Prabandhan : Indian Journal of Management, Vol. 10, $\mathrm{N}^{\circ} 10,2017$, pp. 7-23.

[140] Ramazan Y1lmaz et Fatih Mehmet Bulut : « The Effect Of HRM On Organizational Performance », KNUV, Vol. 2, N 44, 2015, pp. 5-13.

[141] Rana M-H. et Malik M-S. : «Impact of human resource (HR) practices on organizational performance: Moderating role of Islamic principles », International Journal of Islamic and Middle Eastern Finance and Management, Vol. 10, N 2, 2017, pp.186-207.

[142] Reiche B-S., Carr C. et Pudelko M. : «The Role Of Culture At Different Levels Of Analysis », International Journal Of Cross Cultural Management, Vol. 10, N², 2010, pp ; 131-136.

[143] Rhee J., Zhao et Kim C. : « Effects of HRMP on Chinese Firms Organizational Performance : The Moderating Effect of CEO Support », Asian Social Science, Vol. 10, N 13, 2014, pp. 210-221.

[144] Rhodes J., Walsh P. et Lok P. : « Convergence and divergence issues in strategic management - Indonesia's experience with the Balanced Scorecard in Human Resources Management », The international of Human Resource Management, Vol. 19, $\mathrm{N}^{\circ} 6,2008$, pp. $1170-1185$.

[145] Rode J-C., Huang X. et Flynn B. : « A cros-cultural examination of the relationships among human resource management practices and organisational commitment: An institutional collectivism perspective », Human Resource Management Journal, Vol. 26, $\mathrm{N}^{\circ}$ 4, 2016, pp. 471-489.

[146] Sagwa E-V., Evans V., K’Obonyo P. et Ogutu M. : « HRMP And Performance Firms Listed On The Nairobi Securities Exchange », European Journal of Business and Management, Vol. 7, N 14, 2015, pp. 89-96.

[147] Saira H. : « Impact of HRMP on Employees Performance », International Journal of Academic Research in Accounting, Finance and Management Sciences, Vol. 6, N 1, January 2016, pp. 15-22.

[148] Saridakis G., Lai Y. et Cooper C-L. : «Exploring the relationship between HRM and firm performance : A meta-analysis of longitudinal studies », Human Research Management Review, Vol. 27, 2017, pp. 87-96.

[149] Saridakis G., Lai Y., Muñoz Torres R-I. et Gourlay S. : «Exploring the relationship between job satisfaction and organizational commitment: an instrumental variable approach », The International Journal of Human Resource Management, January 2018.

[150] Sedok K. : « Les pratiques de GRH et les performances des PME au Togo : Approche configurationnelle Idéal-type », 6ième édition des SERGe Days, Avril 2018, Dakar, Sénégal. 
[151] Schuler R-S. et Rogovsky N. : «Understanding compensation practice variations across firms : the impact of national culture », Journal of International Business Studies, Vol. 29, N 1, 1998, pp. 159-177.

[152] Sun L-Y., Aryee S. et Law K-S. : «High-performance human resource practices, citizenship behavior, and organizational performance : A relational perspective », Academy of Management Journal, Vol. 50, $\mathrm{N}^{\circ}$ 3, 2007, pp. 558-577.

[153] Taras V., Kirkman B-L. et Steel P. : « Examining the Impact of Culture's Consequences : A Three Decade, Multi-Level, Meta-Analytic Review of Hofstede‘s Cultural Value Dimensions », Journal of Applied Psychology, Vol. 95, $\mathbf{N}^{\circ}$ 3, 2010, pp. 405-439.

[154] Torlak N-G., Kuzey C. et Ragom M. : « Human resource management, commitment and performance links in Iran and Turkey », International Journal of Productivity and Performance Management, Vol. 67, N² 2, June 2018.

[155] Trudel J-M., Saba T. et Guérin G. : «L'influence contrastée des pratiques de gestion des ressources humaines sur l'engagement organisationnel et la performance au travail », Revue Internationale sur le Travail et la Société, Vol. 3, 2005, pp. 406-435.

[156] Trudel J-M., Saba T. et Guérin G. : «L'influence contrastée des pratiques de gestion des ressources humaines sur l'engagement organisationnel et la performance au travail », Pratiques, Vol. 1, No 25, 2005, pp. 1705-6616.

[157] Valverde-Moreno M., Torres-Jiménez M., Lucia-Casademunt A-M. et Muñoz-Ocaña Y. : «Cross Cultural Analysis of Direct Employee Participation: Dealing With Genderand Cultural Values », Frontiers in Psychology, Vol. 10, N $^{\circ} 723$, 2019, pp. 1-13.

[158] Vlachos L.: «The effect of human resource practices on organizational performance : Evidence from Greece », The International Journal of Human Resource Management, Vol. 19, $\mathrm{N}^{\circ}$ 1, 2008, pp. $74-97$.

[159] Wright P-M. et Haggerty J-J. : « Missing variables in theories of strategic human resource management : Time, cause, and individuals », Working paper series, Center for Advenced Human Resource Studies (CAHRS Working Paper \#05-03). Ithaca, NY: Cornell University, School of Industrial and Labor Relations, 2005, https://digitalcommons.ilr.cornell.edu/cahrswp/3

[160] Wright P-M., Gardner T-M., Moynihan L-M. et Allen M-R. : " The relationship between HR practices and firm performance : Examining causal order », Personnel Psychologie, Vol 58, N 2, 2005, pp. 409-446.

[161] Wright P-M. et Kehoe R-R. : « Human resource practices and organizational commitment : A deeper examination », Asia Pacific Journal of Human Resources, Vol.46, N 1, 2008, pp. 6-20.

[162] Wu P-C. et Chaturvedi S.: «The role of procedural justice and power distance in the relationship between high performance work systems and employee attitudes : A multilevel perspective », Journal of Management, Vol. 35, $\mathrm{N}^{\circ}$ 5, 2009, pp. 1228-1247.

[163] Yang L-Q., Spector P-E., Sanchez J-I., Allen T-D., Poelmans S., Cooper C-L. et Antoniou A-S. : «Individualismcollectivism as a moderator of the work demands-strains relationship : A cross-level and cross-national examination », Journal of International Business Studies, Vol.43, $\mathrm{N}^{\circ} 4,2012$, pp. 424-443.

[164] Yim Y-C-M., Sauer P-L.., Lee W-J. et Macrury I. : « Drivers of attitudes toward luxury brands : A cross-national investigation into the roles of interpersonal influence and brand consciousness », International Marketing Review, Vol. 31 $\mathrm{N}^{\circ}$ 4, 2014, pp. 363-389.

[165]Zaitouni M., Sawalha N. et El Sharif A. : «The Impact of Human Resource Management Practices on Organizational Commitment in the Banking Sector in Kuwait », International Journal of Business and Management, Vol. 6, $N^{\circ}$ 6, 2011, pp. $108-123$.

[166]Zehira C., Üzmez A. et Yildız H. : «The Effect of SHRM Practices on Innovation Performance : The Mediating Role of Global Capabilities », 12th International Strategic Management Conference (ISMC), 28-30 October 2016, Antalya, Turkey, Procedia - Social and Behavioral Sciences Vol. 235, 2016, pp. 797-806.

[167]Zhang M., Di Fan D. et Zhu C-J. : « High-performance work systems, corporate social performance and employee outcomes : Exploring the missing links », Journal of Business Ethics, Vol. 120, N 3, 2014, pp. 423-435. 